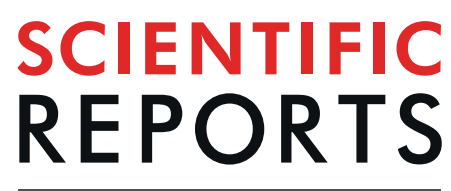

natureresearch

\title{
Pioglitazone Modulates the Vascular Contractility in Hypertension by Interference with ET-1 Pathway
}

Roberto Palacios-Ramírez $\mathbb{1}^{1,2,4,5}$, Raquel Hernanz ${ }^{1,2,5}$, Angela Martín $\mathbb{D}^{1,2}$, José V. PérezGirón ${ }^{1,6}$, María T. Barrús $\mathbb{1}^{1,2}$, Zoe González-Carnicero ${ }^{1}$, Andrea Aguado ${ }^{3}$, Frederic Jaisser ${ }^{4}$, Ana M. Briones ${ }^{2,3}$, Mercedes Salaices ${ }^{2,3}$ \& María J. Alonso ${ }^{1,2^{*}}$

Endothelin-1 (ET-1) is an important modulator of the vascular tone and a proinflammatory molecule that contributes to the vascular damage observed in hypertension. Peroxisome-proliferator activated receptors- $\gamma$ (PPAR $\gamma$ ) agonists show cardioprotective properties by decreasing inflammatory molecules such as COX-2 and reactive oxygen species (ROS), among others. We investigated the possible modulatory effect of PPAR $\gamma$ activation on the vascular effects of ET-1 in hypertension. In spontaneously hypertensive rats (SHR), but not in normotensive rats, ET-1 enhanced phenylephrineinduced contraction through $\mathrm{ET}_{\mathrm{A}}$ by a mechanism dependent on activation of TP receptors by $\mathrm{COX}-2$ derived prostacyclin and reduction in NO bioavailability due to enhanced ROS production. In SHR, the PPAR $\gamma$ agonist pioglitazone $\left(2.5 \mathrm{mg} / \mathrm{Kg}\right.$.day, 28 days) reduced the increased $\mathrm{ET}_{\mathrm{A}}$ levels and increased those of $\mathrm{ET}_{\mathrm{B}}$. After pioglitazone treatment of SHR, ET-1 through $\mathrm{ET}_{\mathrm{B}}$ decreased ROS levels that resulted in increased NO bioavailability and diminished phenylephrine contraction. In vascular smooth muscle cells from SHR, ET-1 increased ROS production through AP-1 and NFKB activation, leading to enhanced COX-2 expression. These effects were blocked by pioglitazone. In summary, in hypertension, pioglitazone shifts the vascular $\mathrm{ET}_{\mathrm{A}} / \mathrm{ET}_{\mathrm{B}}$ ratio, reduces $\mathrm{ROS} / \mathrm{COX}-2$ activation and increases $\mathrm{NO}$ availability; these changes explain the effect of ET-1 decreasing phenylephrine-induced contraction.

Peroxisome-proliferator activated receptors (PPARs) are ligand-activated transcription factors that belong to the nuclear hormone receptor superfamily and regulate the expression of genes involved in glucose and lipids metabolism $^{1}$. PPAR $\gamma$ is expressed in all vascular cells, including vascular smooth muscle cells (VSMC) ${ }^{2}$. PPAR $\gamma$ activation reduces reactive oxygen species (ROS) production and inflammatory molecules such as cyclooxygenase-2 (COX-2) by interfering with mitogen-activated protein kinases (MAPK) and/or proinflammatory transcription factors $^{3-6}$, explaining the cardioprotective effect of PPAR $\gamma$ agonists ${ }^{7}$. In this sense, PPAR $\gamma$ ligands antagonize the vascular damage and functional alterations observed in inflammatory pathologies such as hypertension ${ }^{8-10}$.

Endothelin-1 (ET-1), the most important isoform of the endothelin family, is mainly produced by endothelial cells, although other vascular cells, including VSMC, release ET-1 in response to different stimuli ${ }^{11,12}$. ET-1 interacts with two different G-protein-coupled receptors, ET-1 receptor $\mathrm{A}\left(\mathrm{ET}_{\mathrm{A}}\right)$ and ET-1 receptor $\mathrm{B}\left(\mathrm{ET}_{\mathrm{B}}\right)$. In the vasculature, $\mathrm{ET}_{\mathrm{A}}$ receptors are located in the smooth muscle cells and cause sustained vasoconstriction; $\mathrm{ET}_{\mathrm{B}}$ predominate in endothelial cells and mediate vasodilatation by release of endothelium-derived relaxing factors (nitric oxide -NO-, prostacyclin- $\mathrm{PGI}_{2}$ - and/or endothelium-derived hyperpolarizing factor), although a small population of this subtype is present in VSMC causing vasoconstriction in certain vascular beds ${ }^{13}$. In addition to the mentioned vasoconstrictor effect, ET-1 stimulates the renin-angiotensin-aldosterone and sympathetic nervous systems and possesses cardiac positive inotropic and chronotropic effects; then, ET-1 has a pivotal role at

${ }^{1}$ Depto. de Ciencias Básicas de la Salud, Facultad de Ciencias de la Salud, Universidad Rey Juan Carlos, Alcorcón, Spain. ${ }^{2} \mathrm{CIBER}$ de Enfermedades Cardiovasculares, Madrid, Spain. ${ }^{3}$ Depto. de Farmacología, Facultad de Medicina, Universidad Autónoma de Madrid, Instituto de Investigación Hospital La Paz (IdiPaz), Madrid, Spain. ${ }^{4}$ Institut National de la Santé et de la Recherche Médicale Inserm U1138, Cordeliers Institute, Paris VI-University, Paris, France. ${ }^{5}$ These authors contributed equally: Roberto Palacios-Ramírez and Raquel Hernanz. ${ }^{6}$ José V. Pérez-Girón is deceased. *email: mariajesus.alonso@urjc.es 
cardiovascular level ${ }^{14}$. It is well known that ET-1 contributes to the pathophysiological alterations observed in different inflammatory disorders, such as hypertension ${ }^{15-17}$. Thus, endogenous ET-1 seems to mediate some of the deleterious cardiovascular effects attributed to angiotensin II, such as the renal effects, the cardiac fibrosis or hypertrophy ${ }^{18-20}$. Besides its vasoconstrictor effect, subthreshold concentrations of ET-1 increase the contractility to other vasoactive agents ${ }^{21-23}$. Furthermore, ET-1 increases oxidative stress and proinflammatory enzymes such as COX-2 $2^{3,5,24-27}$ that are involved in the hypertension-associated vascular damage ${ }^{28-30}$.

PPAR $\gamma$ activation reduces ET-1 levels ${ }^{31,32}$; in this sense, we have described that, by downregulating ET-1 transcription, pioglitazone inhibits angiotensin II-associated vascular COX-2 expression in hypertension ${ }^{5}$. However, the effect of PPAR $\gamma$ activation on the vascular actions of ET-1 is less known. We hypothesize that glitazones contribute to reduce the hypertension-associated vascular damage by interfering with ET-1-induced vasoactive and proinflammatory effects. For this, in vessels or VSMC from hypertensive rats we have analysed: (1) the effect of a subthreshold concentration of ET-1 on phenylephrine responses as well as the role of NO and COX-2-derived prostanoids in such effect; (2) the mechanisms involved in the ET-1-induced COX-2 expression; (3) the interference induced by the PPAR $\gamma$ agonist pioglitazone of these ET- 1 effects.

\section{Results}

ET-1 enhances phenylephrine contraction in resistance arteries from hypertensive rats via $\mathrm{ET}_{\mathrm{A}}$. In a previous report, we found greater aortic ET-1 mRNA levels in spontaneously hypertensive rats (SHR) compared to Wistar Kyoto (WKY) rats ${ }^{5}$. Here, we also found greater $\mathrm{ET}_{\mathrm{A}} \mathrm{mRNA}$ levels in both aortic (Fig. 1a) and mesenteric segments (Fig. 1b) from SHR than WKY, while those of $\mathrm{ET}_{\mathrm{B}}$ were similar in both strains (Fig. 1a,b). In order to analyse whether this different receptor expression pattern has functional consequences, reactivity experiments were performed. ET-1, at a concentration $(1 \mathrm{nM})$ which does not induce any vasoactive effect, enhanced the phenylephrine-induced contraction in mesenteric resistance arteries (MRA) from SHR (Emax: Control, $113.6 \pm 2.2 \%$; ET-1, $122.8 \pm 2.3 \%, P<0.05 ; \mathrm{pD}_{2}$ : Control, $5.62 \pm 0.02$; ET-1, $\left.5.82 \pm 0.02 ; P<0.05\right)$, without affecting the contraction in WKY arteries (Fig. 1c). The effect of ET-1 on phenylephrine responses was diminished by endothelium removal in arteries from SHR, as shown by the lack of effect of ET-1 in Emax (Control, 117.6 $\pm 1.1 \%$; ET-1, 119.6 $\pm 2.9 \%, P>0.05)$ and by the decreased dAUC values (Fig. 1c). The ET $_{\mathrm{A}}$ antagonist BQ123 $(1 \mu \mathrm{M})$ abolished the effect of ET-1 in intact SHR segments; however, no effect of BQ788 $(1 \mu \mathrm{M})$, an $\mathrm{ET}_{\mathrm{B}}$ antagonist, was observed (Fig. 1d). On the other hand, ET-1 did not affect the vascular mRNA levels of PPAR $\gamma$ (Fig. 1e).

Reduced NO bioavailability, likely by increase of oxidative stress, contributes to the ET-1-induced enhancement of phenylephrine contraction in MRA from SHR. The incubation with the NOS inhibitor N-nitro-L-arginine methyl ester (L-NAME, $0.1 \mathrm{mM}$ ) leftward shifted the phenylephrine contraction in MRAs from SHR, being this effect reduced in ET-1-treated arteries (Fig. 2a), suggesting that ET-1 reduces the negative modulation induced by NO on phenylephrine contraction; in agreement, and despite the increase of eNOS expression induced by ET-1 (Fig. 2b), the basal NO levels were lower in ET-1-incubated segments (Fig. 2c). It is well accepted that ET-1 increases oxidative stress at vascular level ${ }^{24,26,27}$. Accordingly, ET-1 augmented the vascular NADPH oxidase (NOX) activity (Fig. 2d) and the NOX inhibitor ML-171 (0.5 $\mu \mathrm{M})$ reduced the phenylephrine-induced contraction only in ET-1-treated arteries (Fig. 2e). These results suggest that oxidative stress, by reducing NO bioavailability, would contribute to enhance the phenylephrine-induced response after ET-1 treatment. In addition, ET-1 impaired the vasodilator response induced by ACh (Fig. 2f). After L-NAME incubation ACh-induced relaxation was reduced to a similar level in both ET-1 untreated and treated segments (Fig. 2f), suggesting that ET-1 impaired the NO contribution to endothelium-dependent vasodilator responses. In agreement, ACh-induced NO levels were lower after ET-1 incubation than in control segments (Fig. 2g).

COX-2 derivatives acting on TP receptors are involved in ET-1-induced potentiation of phenylephrine contraction in MRA from SHR. We have previously described that ET-1 increases COX-2 expression in VSMCs from SHR ${ }^{5}$. Then, we analysed the contribution of COX-derived prostanoids to the effect of ET-1 on phenylephrine responses in SHR arteries. Both the non-selective COX inhibitor indomethacin $(10 \mu \mathrm{M})$ and the selective COX-2 inhibitor NS398 $(1 \mu \mathrm{M})$, reduced phenylephrine contraction only in ET-1-treated segments (Fig. 3a), suggesting that COX-2-derived vasoconstrictor prostanoids contribute to the increase of phenylephrine response induced by ET-1 in hypertensive animals. The $\mathrm{EP}_{1-3}$ receptor antagonist SC19220 $(10 \mu \mathrm{M})$ did not affect phenylephrine response neither in control nor in ET-1-incubated segments (data not shown); however, the TxA receptor (TP) antagonist SQ29,548 $(1 \mu \mathrm{M})$ reduced phenylephrine contraction only in ET-1-incubated MRA (Fig. 3a). Notably, the $\mathrm{TxA}_{2}$ synthase inhibitor furegrelate $(1 \mu \mathrm{M})$ did not affect phenylephrine-induced con-

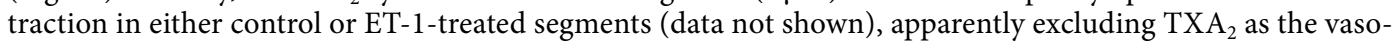
constrictor prostanoid responsible for ET-1-induced hypercontractility. It is well known that $\mathrm{PGI}_{2}$ is the main COX-derived vasodilator prostanoid; however, in some conditions such as hypertension or aging, prostacyclin can induce vasoconstriction via TP receptors ${ }^{10,33}$. We found that the $\mathrm{PGI}_{2}$ synthase inhibitor tranylcypromine $(10 \mu \mathrm{M})$ reduced the phenylephrine contraction only in ET-1-incubated segments (Fig. 3a). In agreement, ET-1 increased PGIS gene expression in VSMC from SHR (relative expression $1.46 \pm 0.13, n=4 ; P<0.05$ ). Together, these results suggest that COX-2-derived $\mathrm{PGI}_{2}$, via TP receptors, contributes to the ET-1-induced enhancement of phenylephrine-response in MRAs from SHR.

In endothelium-denuded segments, NS398 and SQ29,548 still reduced the phenylephrine contraction in ET-1-incubated segments (Fig. 3b), suggesting that ET-1 increased the production of COX-2-derived vasoconstrictor prostanoids from VSMC. 


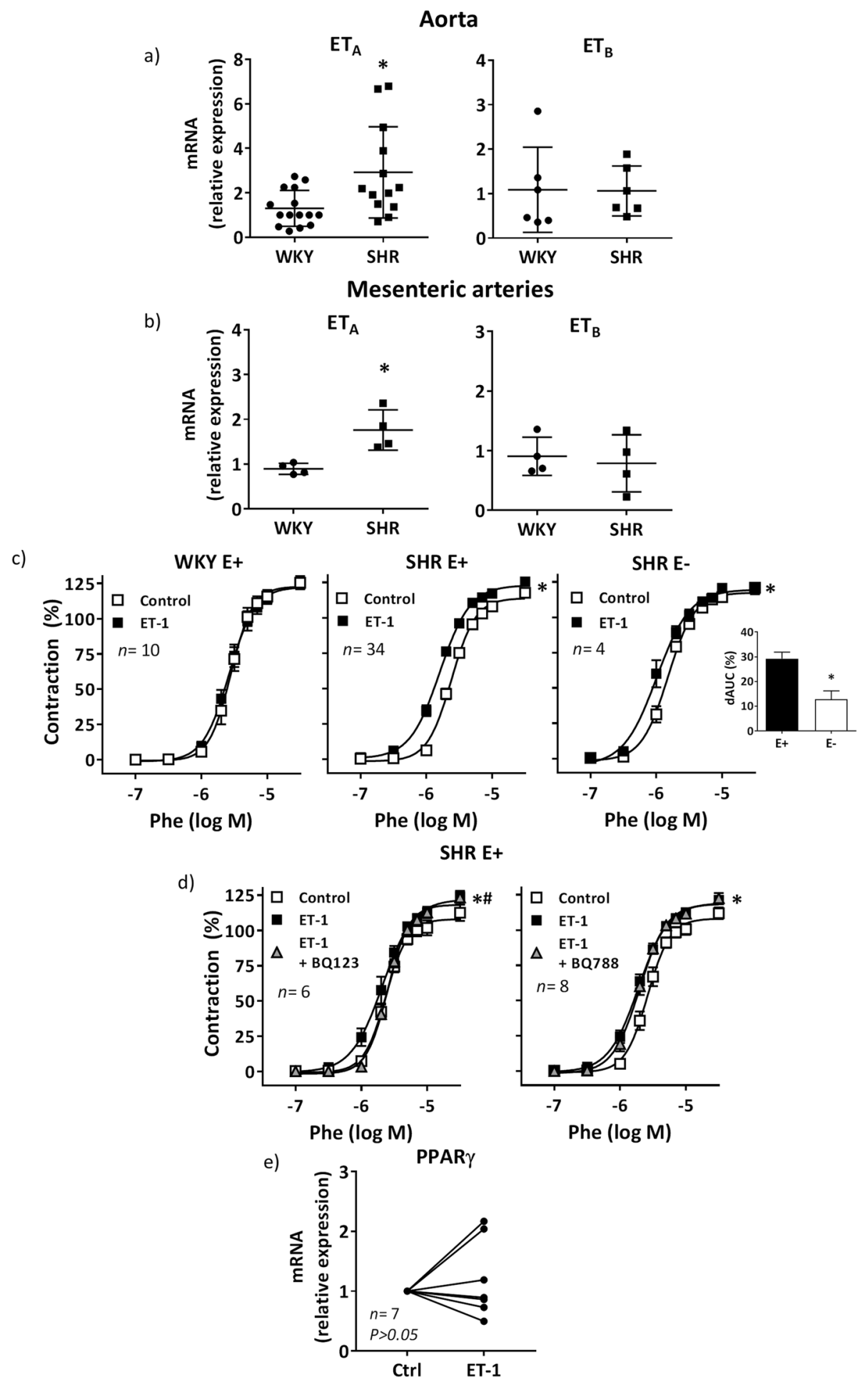

Figure 1. Vascular ET-1 receptors expression and effect of ET-1 on phenylephrine contraction in MRA. $\mathrm{ET}_{\mathrm{A}}$ and $\mathrm{ET}_{\mathrm{B}}$ mRNA levels in aortic (a) and mesenteric (b) segments from WKY and SHR; $* P<0.05$ by Student's $\mathrm{t}$ test. (c) Effect of ET-1 (1 nM, $90 \mathrm{~min})$ on the concentration-response curve to phenylephrine (Phe) in endothelium-intact $(\mathrm{E}+)$ and denuded (E-) segments from WKY and SHR; $* P<0.05$ by two-way ANOVA with repeated measures followed by Sidak post hoc test. Differences of the area under the concentration-response curve (dAUC) to Phe in E+ and E- segments from SHR are also shown; $* P<0.05$ by Student's t test. (d) Effect of BQ123 $(1 \mu \mathrm{M})$ and BQ788 $(1 \mu \mathrm{M})$ on the response to Phe in E+ segments from SHR treated with ET-1; $* P<0.05$ vs control; ${ }^{*} P<0.05$ vs ET- 1 by two-way ANOVA with repeated measures followed by Tukey post hoc test. (e) Effect of ET-1 on the vascular expression of PPAR $\gamma$; statistical analysis by Student's t test. $n$ denotes number of experiments. 
a)
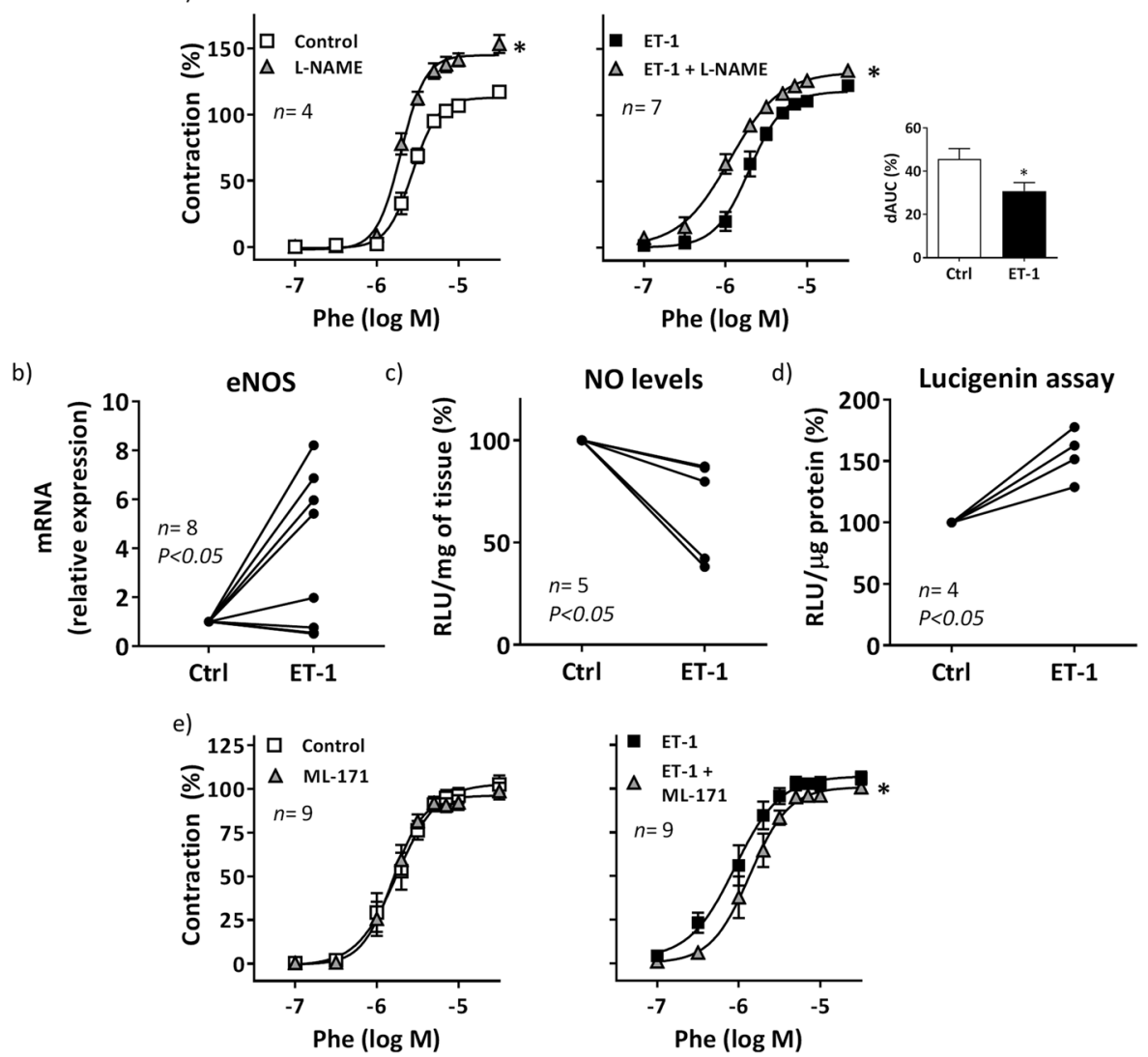

f)

g)
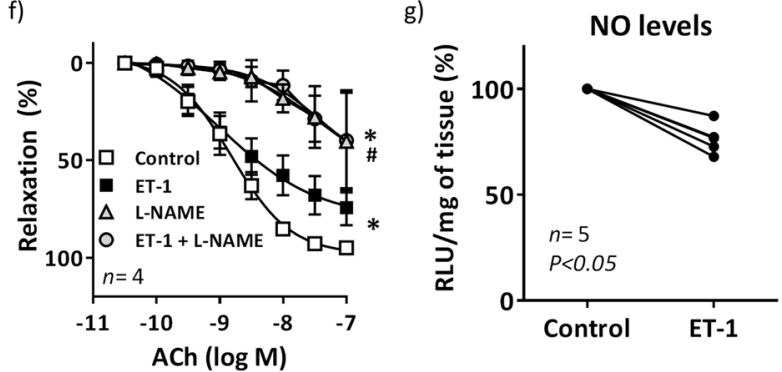

Figure 2. Role of nitric oxide and oxidative stress on ET-1-induced potentiation of phenylephrine response in MRA from hypertensive rats. (a) Effect of $0.1 \mathrm{mM} \mathrm{L-NAME}$ on the concentration-response curve to phenylephrine (Phe) in control and ET-1-incubated ( $1 \mathrm{nM}, 90 \mathrm{~min})$ segments from SHR; $* P<0.05$ by two-way ANOVA with repeated measures followed by Sidak post hoc test. Differences of the AUC (dAUC) to Phe in the presence and the absence of L-NAME are also shown; $* P<0.05$ by Student's $t$ test. (b) Effect of ET- 1 on eNOS mRNA levels in vascular segments; statistical analysis by Student's t test. (c) Quantification of nitric oxide (NO) release and (d) NADPH oxidase activity in control and ET-1-incubated segments from SHR; statistical analysis by Student's t test. (e) Effect of $0.5 \mu \mathrm{M}$ ML-171 on the concentration-response curve to Phe in control and ET-1incubated segments from SHR; $* P<0.05$ by two-way ANOVA with repeated measures followed by Sidak posttest. (f) Effect of ET-1 and L-NAME on the concentration-response curve to acetylcholine (ACh) in segments from SHR; $* P<0.05$ vs Control; ${ }^{*} P<0.05$ vs ET-1 by two-way ANOVA with repeated measures followed by Sidak post hoc test. (g) Quantification of ACh-induced NO release in control and ET-1-incubated segments from SHR; statistical analysis by Student's t test. $n$ denotes number of experiments.

Oxidative stress contributes to ET-1-induced COX-2 expression in VSMC from SHR. Next, we analyzed the mechanisms involved in the induction of COX-2 by ET-1 in cultured VSMCs from SHR. As shown in Fig. $4 \mathrm{a}-\mathrm{c}$ the antioxidant apocynin but not the $\mathrm{H}_{2} \mathrm{O}_{2}$ scavenger catalase $(1,000 \mathrm{U} / \mathrm{ml})$, reduced the ET-1-induced COX-2 expression, suggesting the contribution of superoxide anion to the ET-1-induced COX-2 expression. In agreement, ET-1 $(0.1 \mu \mathrm{M})$ increased NOX-1 protein and mRNA levels (Fig. 4d,e), NOX-4 mRNA levels (Fig. 4f), NADPH oxidase activity and superoxide anion production (Fig. 4g,h). 
SHR

a)
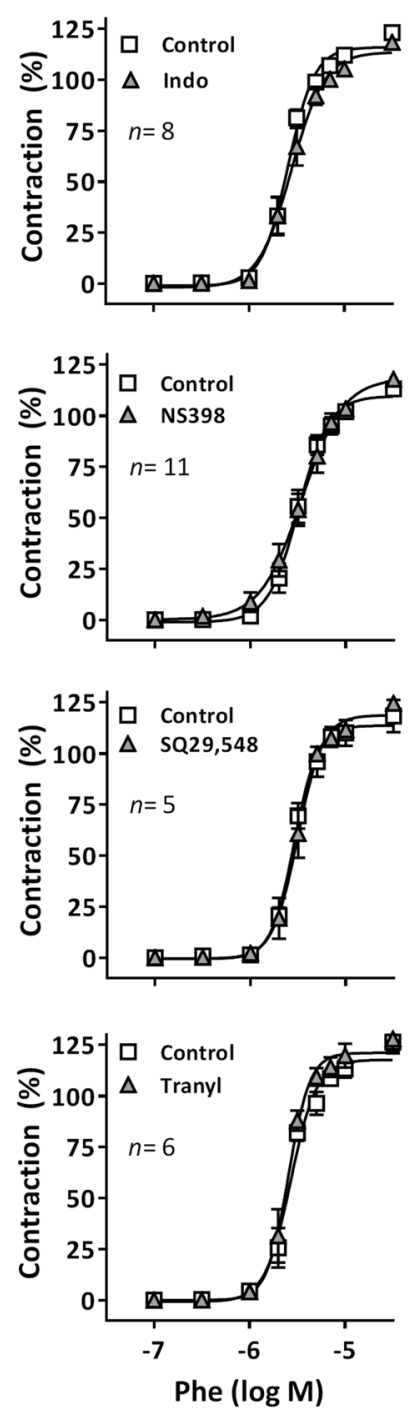

b)

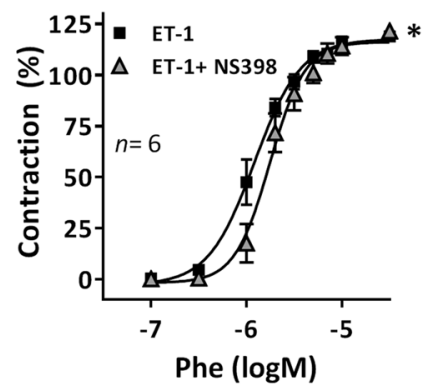

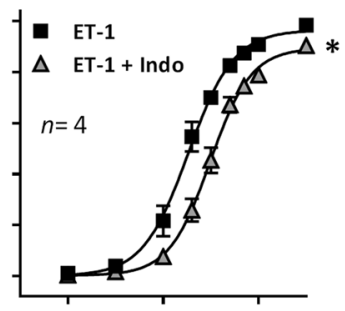
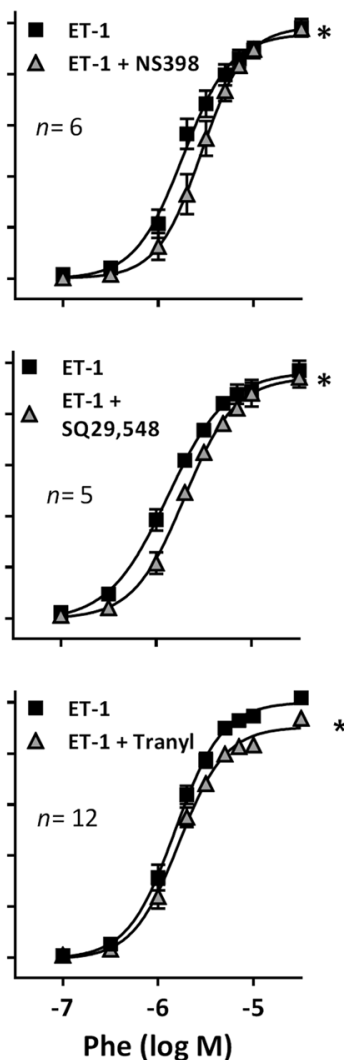

SHR E-

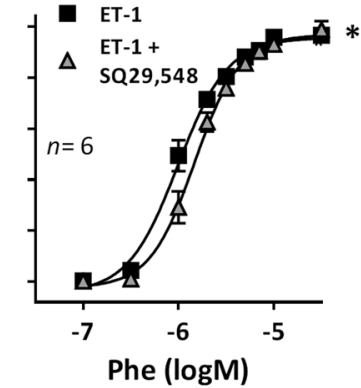

Figure 3. Role of cyclooxygenase-derived prostanoids on ET-1-induced potentiation of phenylephrine response in MRA from hypertensive rats. (a) Effect of $10 \mu \mathrm{M}$ indomethacin (Indo), $1 \mu \mathrm{M}$ NS398, $1 \mu \mathrm{M}$ SQ29,548 and $10 \mu \mathrm{M}$ tranylcypromine (Tranyl) on the concentration-response curve to phenylephrine (Phe) in intact control and ET-1-incubated ( $1 \mathrm{nM}, 90 \mathrm{~min})$ segments from SHR. (b) Effect of NS398 and SQ29,548 on the concentrationresponse curve to Phe in endothelium-denuded (E-) segments from SHR incubated with ET- 1 . $* P<0.05$ by twoway ANOVA with repeated measures followed by Sidak post-test. $n$ denotes number of experiments.

It has been described that ET-1 activates several transcription factors ${ }^{3,34,35}$. We then analysed the contribution of nuclear factor kappa-light-chain-enhancer of activated B cells (NFkB) and activator protein 1 (AP-1) on the ROS/COX-2 pathway. In VSMCs from SHR, the proteasome inhibitor lactacystin $(10 \mu \mathrm{M})$ reduced the 
a)

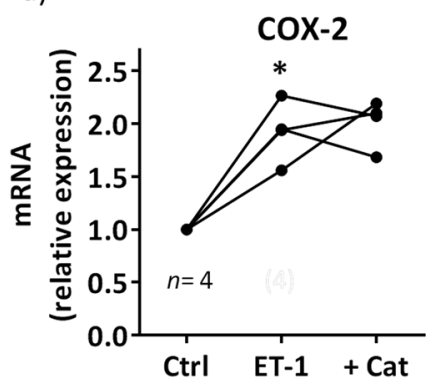

d)

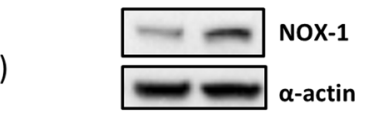

g)

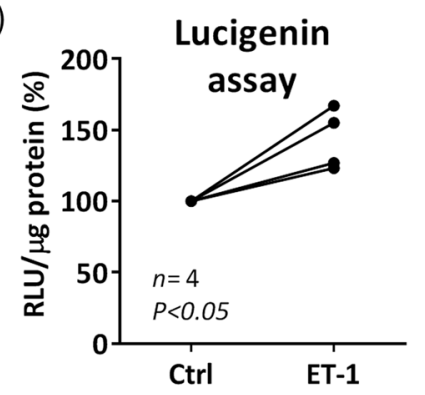

b)

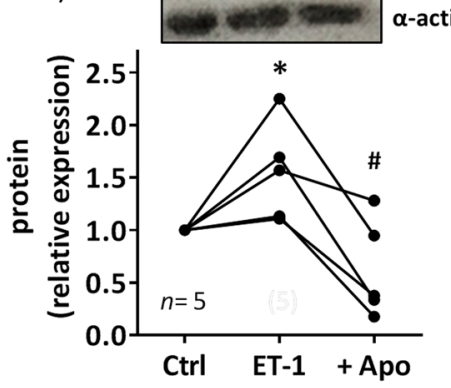

e)

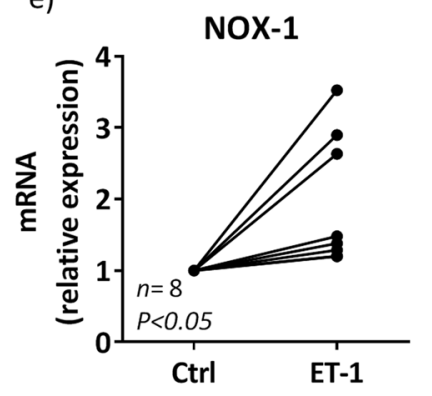

h)
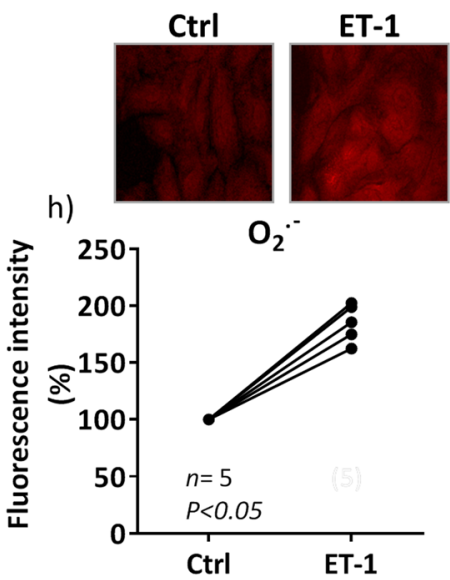

c)

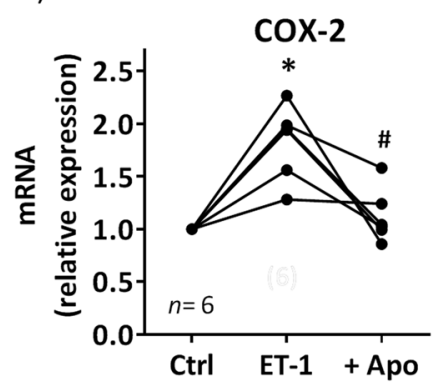

f)

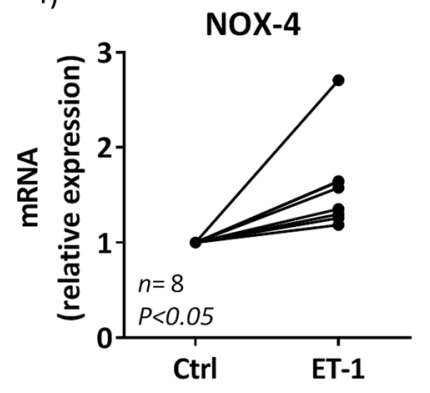

Figure 4. Contribution of oxidative stress to the ET-1-induced COX-2 expression in VSMC from hypertensive rats. (a) Effect of catalase (Cat, 1,000 U/ml) on ET-1 $(0.1 \mu \mathrm{M}, 1 \mathrm{~h})$-induced COX-2 mRNA levels. Effect of apocynin $($ Apo, $30 \mu \mathrm{M})$ on ET-1-induced COX-2 protein expression $(\mathbf{b})$ and mRNA levels (c). Effect of ET-1 on NOX-1 protein expression (d) and mRNA levels (e), NOX-4 mRNA levels (f), NADPH oxidase activity (g) and superoxide anion $\left(\mathrm{O}_{2}^{-}{ }^{-}\right)$production $(\mathbf{h})$ in VSMC from SHR. Statistical analysis by Student's t-test; $* P<0.05$ vs control (Ctrl) and ${ }^{\#} P<0.05$ vs ET-1. $n$ denotes number of experiments. Full-length blots are presented in Supplementary Figs S1 and S2.

ET-1-induced NOX-1 mRNA levels and NADPH oxidase activity (Fig. 5a,b) and COX-2 expression (Fig. 5c,d). In addition, ET-1 increased the nuclear expression of the NFKB p65 subunit (Fig. 5e); the immunofluorescence experiments confirmed the augmented nuclear localization of p65 (Fig. 5f).

The specific JNK inhibitor SP600125 $(20 \mu \mathrm{M})$ also diminished the ET-1-induced NOX-1 expression and NADPH oxidase activity (Fig. 6a,b) as well as COX-2 protein and mRNA levels (Fig. 6c,d). Furthermore, ET-1 increased JNK1/2 phosphorylation and c-jun expression (Fig. 6e,f), supporting the activation of AP-1. Altogether, these results suggest that ET-1 induces COX-2 expression by increasing ROS production through NFKB and AP-1 pathways.

After pioglitazone treatment of SHR, ET-1 increased NO bioavailability reducing phenylephrine contraction in MRA through $\mathrm{ET}_{\mathrm{B}}$ receptors. It is well known that glitazones are cardioprotective compounds with antiinflammatory and antioxidant properties ${ }^{7}$. In previous reports, we showed that pioglitazone improved vascular function and reduced the increased vascular ET-1 expression in SHR ${ }^{5,10}$. Herein we found 
a)

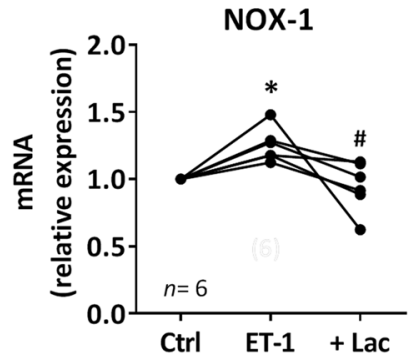

c)

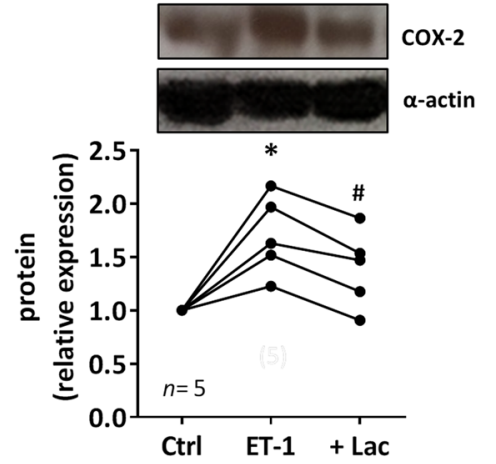

e)

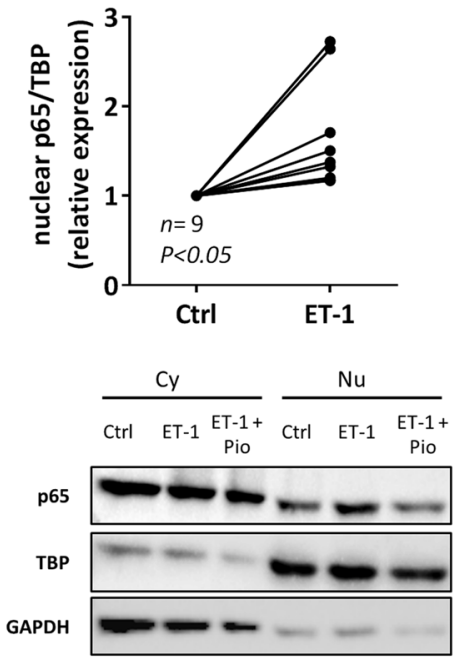

b)

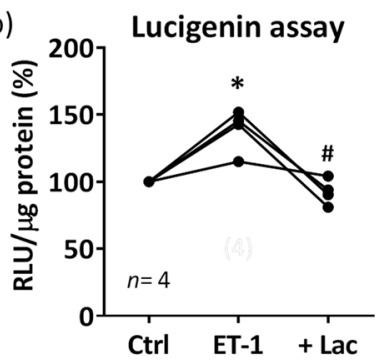

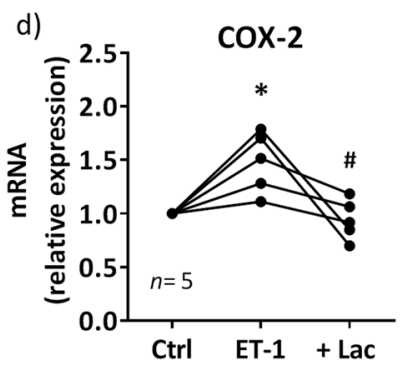

f)

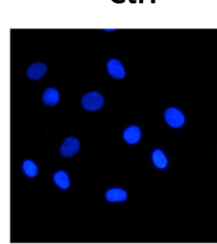

ET-1
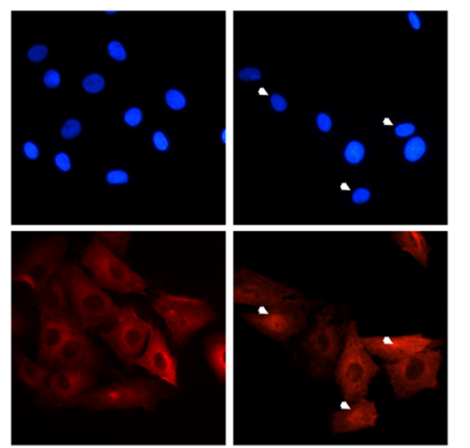

Dapi
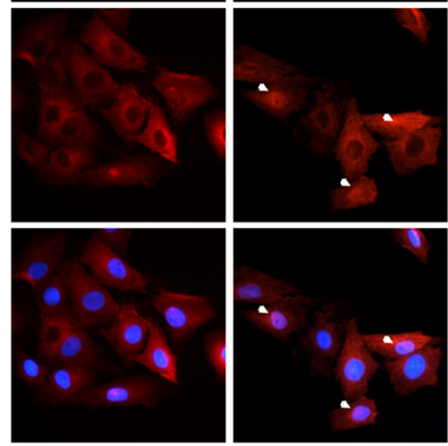

anti-p65

Without Primary Without Secondary antibody antibody
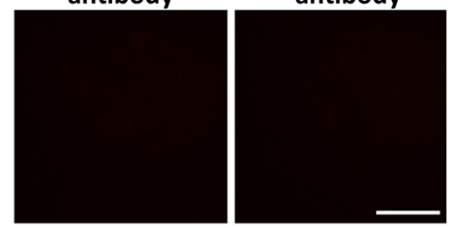

Negative control

Figure 5. Contribution of NFKB to the ET-1-induced oxidative stress and COX-2 expression in VSMC from hypertensive rats. Effect of lactacystin (Lac, $10 \mu \mathrm{M}$ ) on NOX-1 mRNA levels (a), NADPH oxidase activity (b), COX-2 protein expression (c) and mRNA levels (d) induced by ET-1 $(0.1 \mu \mathrm{M}, 1 \mathrm{~h})$. (e) Effect of ET-1 $(0.1 \mu \mathrm{M}, 45 \mathrm{~min})$ on nuclear $\mathrm{p} 65 \mathrm{NF} \kappa \mathrm{B}$ protein expression in VSMC from SHR; a representative blot of the cytosolic (Cy) and nuclear (Nu) expression is shown below; TATA-binding protein (TBP) and GAPDH (after reblotting) cytosolic and nuclear expressions are also shown to guarantee the successful cellular fractioning. (f) Representative photomicrographs of $\mathrm{p} 65 \mathrm{NF} \kappa \mathrm{B}$ immunofluorescence (red) in VSMC from SHR in control and after incubation with ET-1 $(0.1 \mu \mathrm{M}, 45 \mathrm{~min}, n=7)$. Negative controls without primary or secondary antibody are also shown. Bar scale represents $50 \mu \mathrm{m}$. Statistical analysis by Student's t-test; $* P<0.05$ vs control and ${ }^{\#} P<0.05$ vs ET-1. $n$ denotes number of experiments. Full-length blots are presented in Supplementary Fig. S3. 
a)

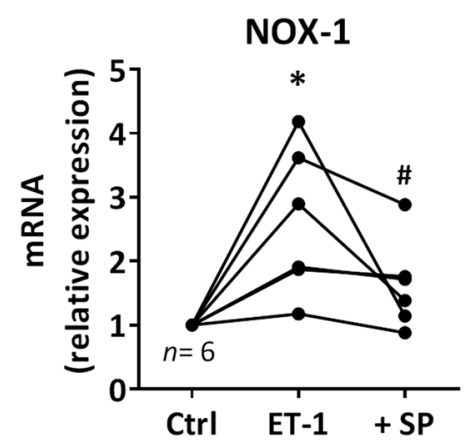

c)

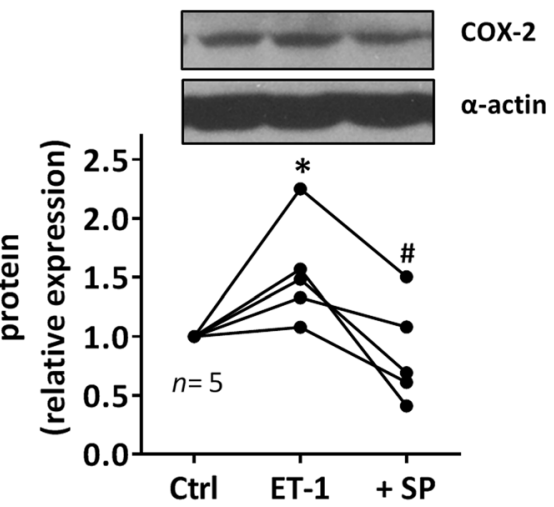

b)

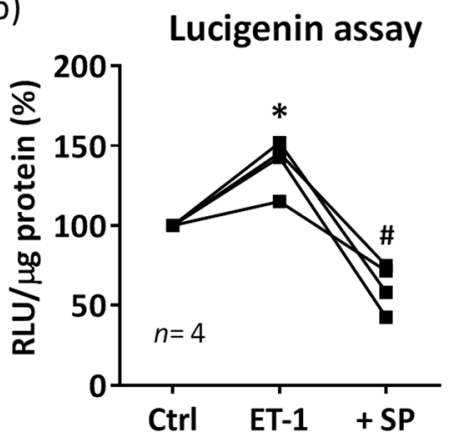

e)

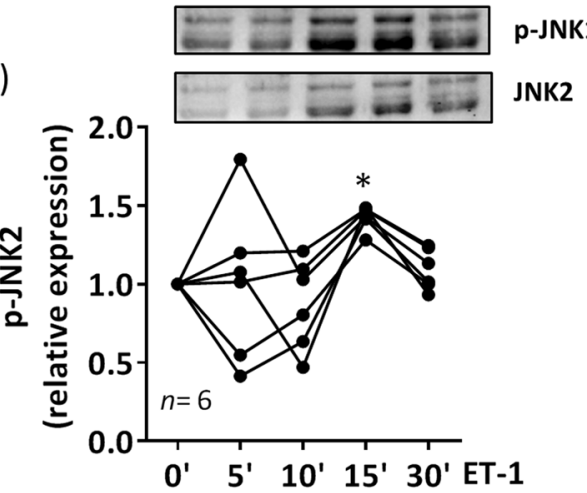

d)

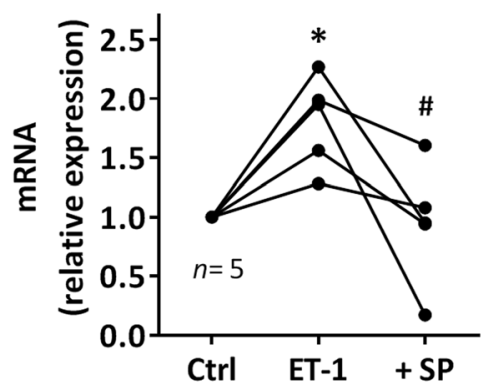

Figure 6. Contribution of AP-1 to the ET-1-induced oxidative stress and COX-2 expression in VSMC from hypertensive rats. Effect of SP600125 (SP, $20 \mu \mathrm{M})$ on NOX-1 mRNA levels (a), NADPH oxidase activity (b) and COX-2 protein expression (c) and mRNA levels (d) induced by ET-1 $(0.1 \mu \mathrm{M}, 1 \mathrm{~h}) . * P<0.05$ vs control (Ctrl) and ${ }^{\#} P<0.05$ vs ET- 1 by Student's t-test. (e) Time-course of ET- $1(0.1 \mu \mathrm{M})$-induced $\mathrm{p}$-JNK1/2 protein expression in VSMC from SHR; $* P<0.05$ vs control $\left(0^{\prime}\right)$ by one-way ANOVA. A representative blot is shown in the upper panel; lower panel shows reblotting of upper panel with JNK2 antibody. (f) Effect of ET-1 $(0.1 \mu \mathrm{M}$, $1 \mathrm{~h}$ ) on c-jun mRNA levels. Statistical analysis by Student's t-test. $n$ denotes number of experiments. Full-length blots are presented in Supplementary Fig. S4.

that pioglitazone treatment reduced $\mathrm{ET}_{\mathrm{A}}$ and increased $\mathrm{ET}_{\mathrm{B}}$ transcription in aortic and mesenteric segments (Fig. 7a,b). These changes had functional consequences. Thus, in pioglitazone-treated rats, ET-1 reduced phenylephrine contraction, effect prevented by the $\mathrm{ET}_{\mathrm{B}}$ antagonist $\mathrm{BQ} 788$ but not by the $\mathrm{ET}_{\mathrm{A}}$ antagonist $\mathrm{BQ} 123$ (Fig. $7 \mathrm{c}$ ).

In pioglitazone-treated SHR, L-NAME leftward shifted phenylephrine response in control arteries (Fig. 7d). Notably, the effect of L-NAME was greater in arteries incubated with ET-1 (Fig. 7d), suggesting increased NO availability. Previously we have shown that ET-1 decreased the NO levels; after pioglitazone incubation, the NO levels were increased in ET-1-treated arteries; this increased in NO levels was prevented by BQ788 (Fig. 7e). Additionally, pioglitazone incubation improved the reduction on ACh-induced NO levels observed after ET-1 (NO levels relative to control: ET-1, $76.3 \pm 3.2 \%$; ET- $1+$ Pio, $97.0 \pm 8.3 \%, n=5, P<0.05$ ). On the other hand, the NADPH oxidase activity observed in ET-1-treated arteries was reduced by pioglitazone (Fig. 7f). Altogether, these results suggest that after pioglitazone treatment, $\mathrm{ET}-1 / \mathrm{ET}_{\mathrm{B}}$ pathway increases $\mathrm{NO}$ bioavailability reducing phenylephrine response; the antioxidant properties of pioglitazone likely contribute to this effect. 
a)

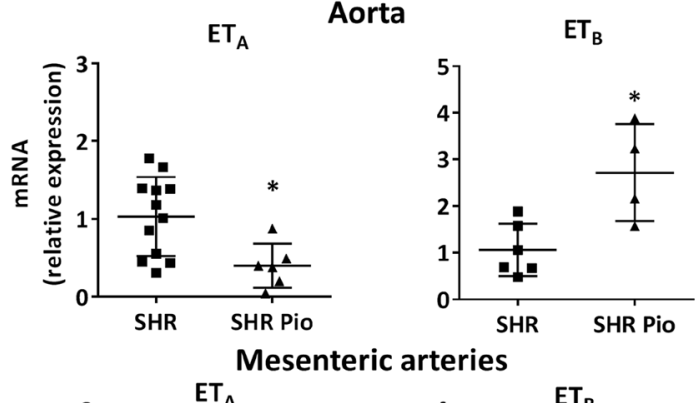

b)

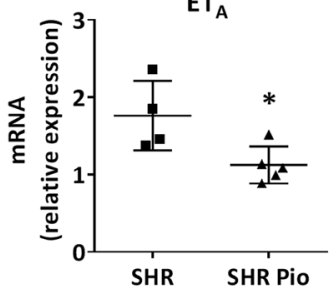

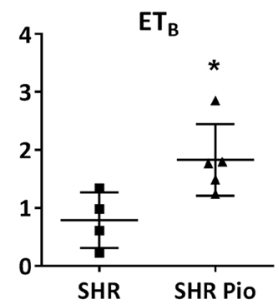

SHR Pio

c)
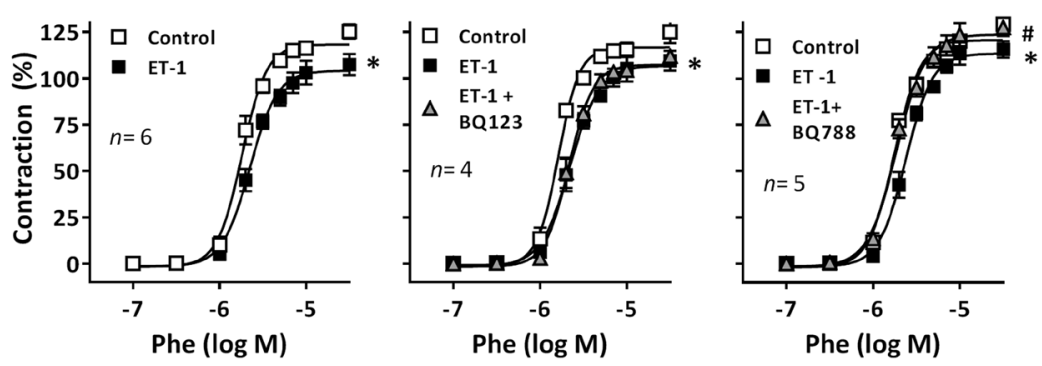

d)

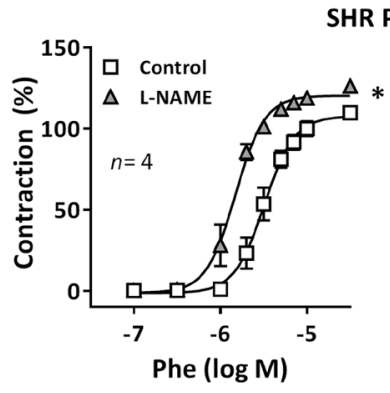

HR Pio
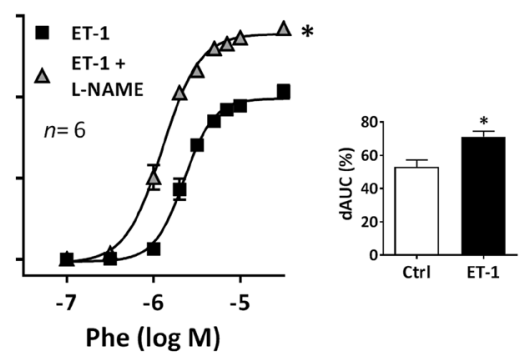

e)

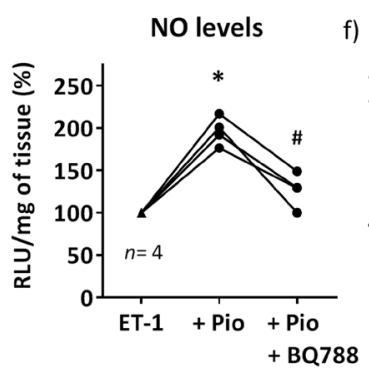

f)

Lucigenin assay

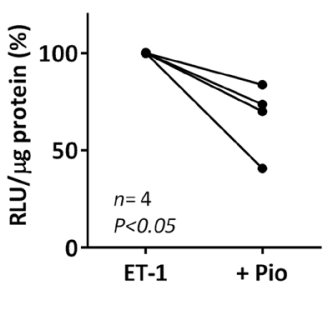

Figure 7. Effect of pioglitazone treatment of hypertensive rats on the vascular ET-1 receptors expression and ET-1 effect on phenylephrine contraction in MRA. Role of nitric oxide. $\mathrm{ET}_{\mathrm{A}}$ and $\mathrm{ET}_{\mathrm{B}} \mathrm{mRNA}$ levels in aortic (a) and mesenteric (b) segments from SHR untreated and treated with pioglitazone (Pio, $2.5 \mathrm{mg} / \mathrm{Kg}$.day, 28 days); ${ }^{*} P<0.05$ by Student's t test. (c) Effect of ET-1 $(1 \mathrm{nM}, 90 \mathrm{~min})$ and ET-1 plus BQ123 $(1 \mu \mathrm{M})$ or BQ788 $(1 \mu \mathrm{M})$ on the concentration-response curve to phenylephrine (Phe) in endothelium-intact segments from pioglitazone (Pio)-treated SHR; $* P<0.05$ vs control; ${ }^{*} P<0.05$ vs ET- 1 by two-way ANOVA with repeated measures followed by Sidak or Tukey post hoc test. (d) Effect of $0.1 \mathrm{mM} \mathrm{L-NAME}$ on the response to Phe in control and ET-1incubated segments from SHR treated with pioglitazone; $* P<0.05$ by two-way ANOVA with repeated measures followed by Sidak post hoc test. Differences of the AUC (dAUC) to Phe in the presence and the absence of L-NAME are also shown; ${ }^{*} P<0.05$ by Student's $t$ test. (e) Quantification of nitric oxide (NO) levels in vascular segments from SHR incubated with ET-1 $(0.1 \mu \mathrm{M}, 1 \mathrm{~h})$ in the absence or the presence of Pio $(10 \mu \mathrm{M}, 18 \mathrm{~h})$ and BQ788 $(1 \mu \mathrm{M})$; ${ }^{*} P<0.05$ vs ET- 1 and ${ }^{\#} P<0.05$ vs ET-1+Pio by Student's t-test. (f) Quantification of NADPH oxidase activity in vascular segments from SHR incubated with ET-1 $(0.1 \mu \mathrm{M}, 1 \mathrm{~h})$ in the absence or the presence of Pio $(10 \mu \mathrm{M}, 18 \mathrm{~h})$; statistical analysis by Student's t test. $n$ denotes number of experiments. 

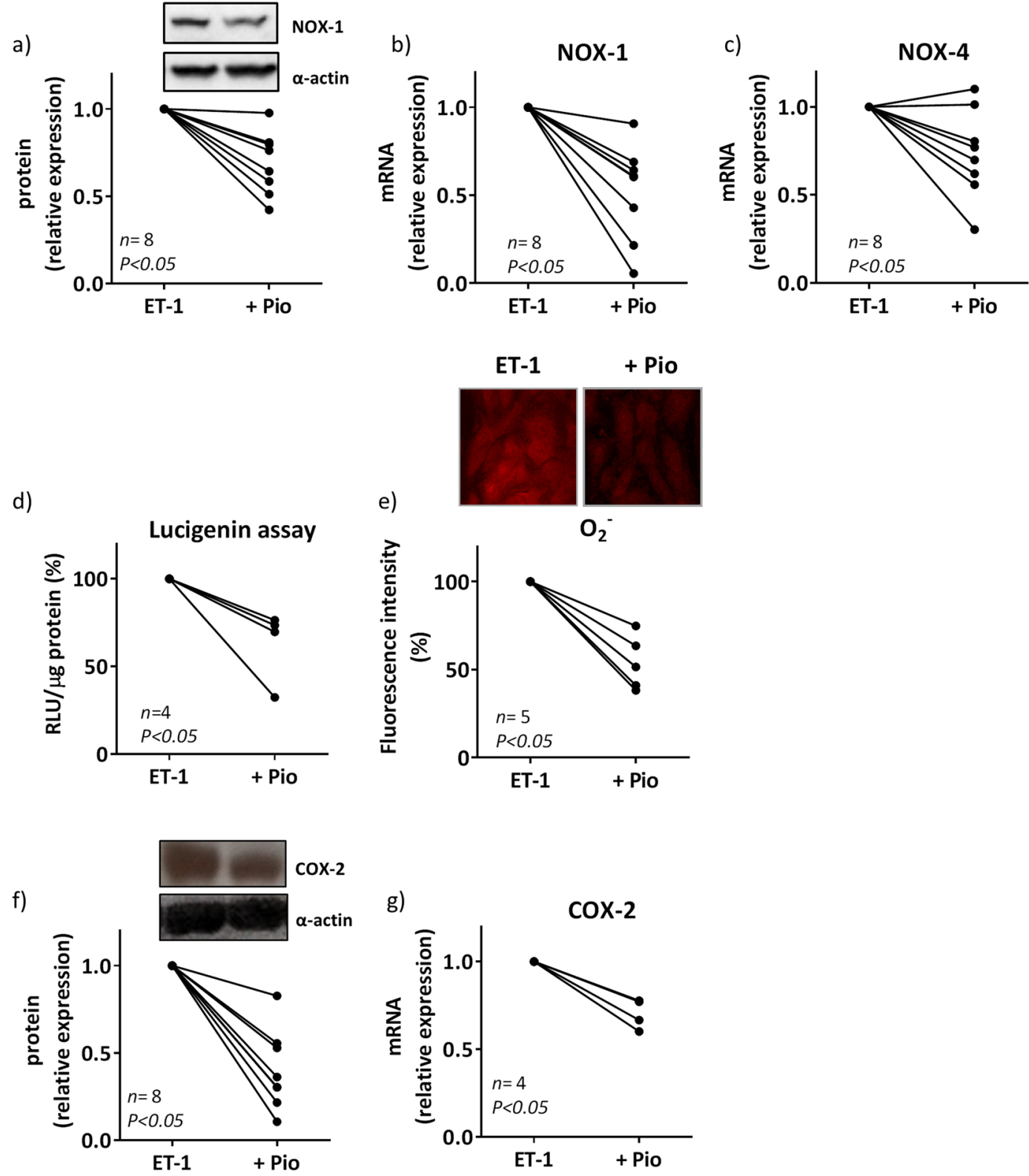

Figure 8. Effect of pioglitazone on the role of oxidative stress to the ET-1-induced COX-2 expression in VSMC from hypertensive rats. Effect of pioglitazone (Pio, $10 \mu \mathrm{M}, 18 \mathrm{~h})$ on ET-1 $(0.1 \mu \mathrm{M}, 1 \mathrm{~h})$-induced NOX-1 protein expression (a) and mRNA levels (b), NOX-4 mRNA levels (c), NADPH oxidase activity (d), superoxide anion $\left(\mathrm{O}_{2}^{-}\right)$production (e), and COX-2 protein expression (f) and mRNA levels $(\mathbf{g})$ in vascular smooth muscle cells from SHR. Statistical analysis by Student's t-test. $n$ denotes number of experiments. Full-length blots are presented in Supplementary Figs S2 and S5.

Pioglitazone downregulates ET-1-induced COX-2 expression by interference with NFKB and AP-1 activation and reduction of ROS production in VSMC from SHR. In VSMCs from SHR, pioglitazone prevented ET-1-induced increase of NOX-1 protein and mRNA levels, NOX-4 mRNA levels, NADPH oxidase activity and superoxide anion production (Fig. 8a-e). In addition, pioglitazone reduced ET-1-induced COX-2 mRNA and protein levels (Fig. 8f,g) as well as the mRNA levels of the $\mathrm{PGI}_{2}$ synthase (relative expression: $0.71 \pm 0.06, n=4, P<0.05)$.

Glitazones interfere with NFKB and AP-1 activation by transrepression mechanisms ${ }^{5,36}$. Accordingly, pioglitazone diminished p65 nuclear expression (Fig. 9a,b; representative blot in Fig. 5e), JNK1/2 phosphorylation (Fig. 9c) and c-jun mRNA levels induced by ET-1 (Fig. 9d) in VSMCs from SHR. These results suggest that pioglitazone, by interfering with $\mathrm{AP}-1$ and $\mathrm{NF} \kappa \mathrm{B}$, might reduce ROS production and COX-2 expression. 
a)

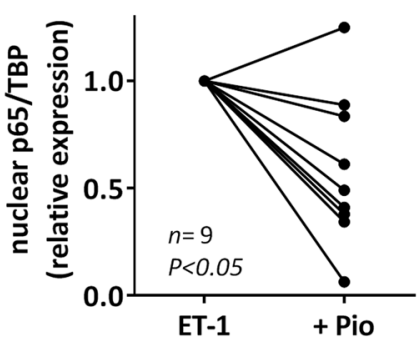

c)

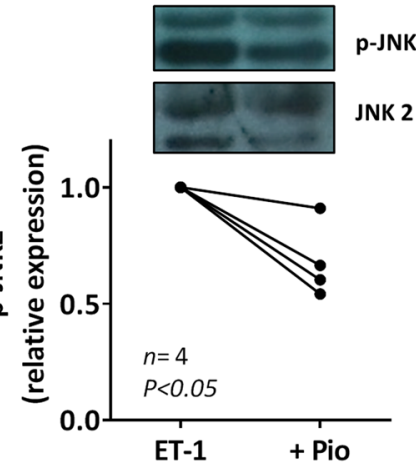

b)
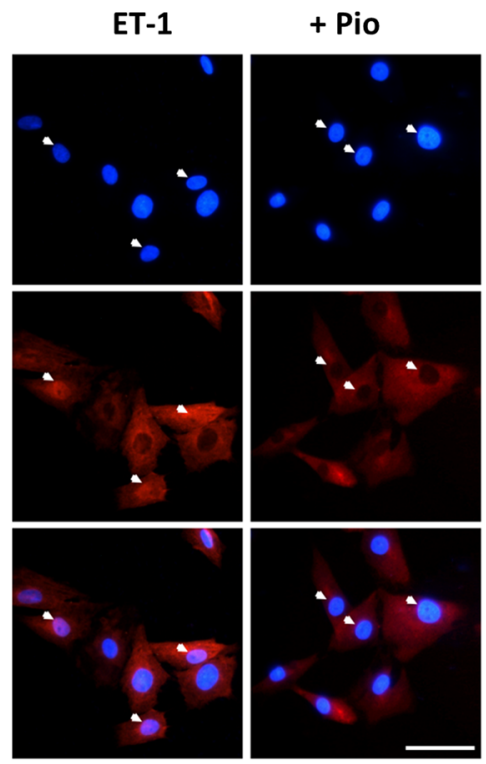

Dapi

anti-p65

anti-p65

$+$

Dapi

d)

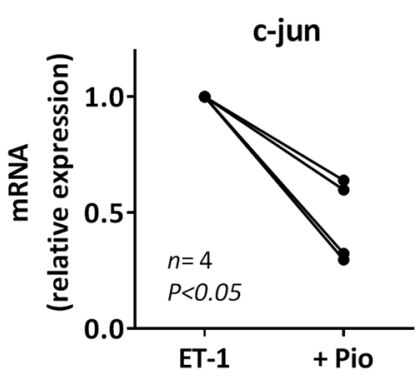

Figure 9. Effect of pioglitazone on the role of NFKB and AP-1 to the ET-1-induced COX-2 expression in VSMC from hypertensive rats. (a) Effect of pioglitazone (Pio, $10 \mu \mathrm{M}, 18 \mathrm{~h})$ on ET-1 $(0.1 \mu \mathrm{M}, 45 \mathrm{~min})$-induced nuclear p65 NFKB protein expression in vascular smooth muscle cells (VSMC) from SHR; the representative blot of the cytosolic (Cy) and nuclear (Nu) expression is shown in Fig. 5E. (b) Representative photomicrographs of p65 NFKB immunofluorescence (red) in VSMC from SHR after incubation with ET-1 $(0.1 \mu \mathrm{M}, 45 \mathrm{~min})$ in the absence and in the presence of pioglitazone. Bar scale represents $50 \mu \mathrm{m}$. Effect of pioglitazone on (c) p-JNK1/2 protein expression (a representative blot is shown in the upper pane; lower panel shows reblotting of upper panel with JNK2 antibody) and (d) c-jun mRNA levels induced by ET-1 ( $0.1 \mu \mathrm{M}, 15$ min for p-JNK2 and $1 \mathrm{~h}$ for c-jun). Statistical analysis by Student's t-test. $n$ denotes number of experiments. Full-length blots are presented in Supplementary Fig. S6.

\section{Discussion}

In the present study, we found that ET-1, through $\mathrm{ET}_{\mathrm{A}}$, increased phenylephrine response in SHR by mechanisms involving production of vasoconstrictor prostanoids from COX-2 and reduction of NO bioavailability, probably because of increased oxidative stress. Pioglitazone treatment of hypertensive animals decreased $\mathrm{ET}_{\mathrm{A}}$ and increased $\mathrm{ET}_{\mathrm{B}}$ expression. In these conditions, ET-1 acting on $\mathrm{ET}_{\mathrm{B}}$, increased $\mathrm{NO}$ production and reduced phenylephrine-induced contraction. The antioxidant effect of pioglitazone likely contributed to decrease the COX-2 expression and to increase the NO bioavailability.

ET-1 levels are increased in some hypertension models ${ }^{5,37}$ and this peptide plays a role in hypertension-associated vascular damage ${ }^{38,39}$. ET-1 regulates vascular tone not only by inducing vasoconstriction but also by modulating the response to other vasoactive agents; in addition, the proinflammatory properties of ET-1 seem to contribute to its hypertensinogenic effect ${ }^{21,22,40}$. Here we found greater $\mathrm{ET}_{\mathrm{A}}$ expression in vessels from SHR than WKY that likely explains the effect of a subthreshold concentration of ET-1 on elevating phenylephrine-induced responses only in SHR. This is in agreement with previous studies showing increased $\mathrm{ET}_{\mathrm{A}}$ levels in vessels from hypertensive animals ${ }^{41}$ and the involvement of this receptor in the vascular effects of ET- $1^{40,42,43}$; however, the contribution of $\mathrm{ET}_{\mathrm{B}}$ from VSMC to the vasomotor ET-1 effects in hypertension has also been reported ${ }^{44}$. In this study we did not find alterations in $\mathrm{ET}_{\mathrm{B}}$ expression or functional effects in hypertension.

L-NAME and endothelium removal increased the phenylephrine contraction in MRA from SHR, being this effect reduced after ET-1 incubation, suggesting that after ET-1, the NO contribution to phenylephrine-induced response is reduced; additionally, ET-1 reduced the basal NO levels, suggesting that, although induces eNOS 
transcription, ET-1 reduces the NO bioavailability, thus contributing, at least partially, to the increased phenylephrine contraction. In agreement to our results, after NO inhibition, ET-1 failed to further increase the contraction to electrical stimulation and 5-HT, as compared with that obtained in the absence of this peptide ${ }^{22,42}$. Accordingly with that found by other authors ${ }^{24-26}$, after incubation with ET-1 we found increased NADPH oxidase activity; along with this, the NOX inhibitor ML-171 reduced the contraction to phenylephrine in segments from ET-1-treated arteries. All these results suggest that the mechanism responsible for the increased phenylephrine-induced contraction elicited by ET-1 would be the production of ROS from NADPH oxidase reducing NO bioavailability. These would also explain the impairment of ACh-induced relaxation observed after ET-1 incubation. Additional mechanisms include activation of TP receptors by $\mathrm{PGI}_{2}$, as shown by the inhibitory effect of the $\mathrm{PGI}_{2}$ synthase inhibitor tranylcypromine in phenylephrine-induced contraction in ET-1-incubated segments. Although $\mathrm{PGI}_{2}$ is generally associated with vasodilator and antiagregant properties, in conditions such as hypertension or aging $\mathrm{PGI}_{2}$ binds TP receptors acting as a vasoconstrictor ${ }^{10,33}$. In addition, this COX-2-derived $\mathrm{PGI}_{2}$ is likely produced in VSMC since both NS398 and SQ29,548 reduced the effect of ET-1 on phenylephrine contraction also in endothelium denuded arteries. In agreement, ET-1 induced COX-2 and $\mathrm{PGI}_{2}$ synthase expression in VSMC from SHR. The enhanced COX-2 expression was dependent on oxidative stress because the antioxidant apocynin decreased ET-1-induced COX-2 expression and ET-1 increased NOX-1, NOX-4 and NADPH oxidase activity in SHR VSMC. Other authors have described that ET-1 increases ROS production ${ }^{24-27}$ as well as the involvement of oxidative stress in the COX-2 expression induced by several stimuli in different cell types ${ }^{45}$.

The transcription factor NFKB is a downstream element of ET-1 signalling and its involvement in ET-1-induced COX-2 expression has been described in VSMC from SHR-SP ${ }^{3}$. In order to analyze the contribution of NFKB pathway, we used lactacystin, a natural nonpeptidic proteasome inhibitor that prevents degradation

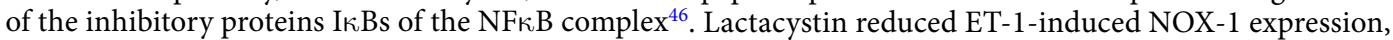
NADPH oxidase activity and COX-2 expression in SHR VSMC, supporting the role of NFKB on ET-1/ROS/ COX-2 pathway. In agreement, ET-1 increased the nuclear translocation of the p65 NFkB subunit. Moreover, AP-1 seems to play a role in ET-1-induced ROS/COX-2 expression because ET-1 increased JNK1/2 phosphorylation and c-jun mRNA levels in cells from SHR and SP600125 reduced ET-1-induced oxidative stress and COX-2 expression. In agreement, AP-1 dependent modulation of COX-2 was described in endothelial cells from brain mouse ${ }^{47}$, although other authors also showed COX-2 modulation by other kinases in response to ET-1 in microvascular VSMC ${ }^{48}$; therefore, we cannot exclude the contribution of other signalling pathways in the ET-1 effect observed in our conditions.

PPAR $\gamma$ agonists have cardioprotective effects associated, among others, with improvement of vascular inflammation $^{7}$. Additionally, we and others have described that pioglitazone reduces ET-1 production, which might also contribute to its cardioprotective properties ${ }^{5,31,32,49}$. Furthermore, PPAR $\gamma$ regulates ET-1 activated processes such as vasoconstriction ${ }^{50}$ and cardiac hypertrophy ${ }^{51,52}$ and a recent report suggests that specific VSMC PPAR $\gamma$ counteracts ET-1-induced vascular damage ${ }^{6}$. Among the mechanisms responsible for these effects, earlier studies demonstrated that rosiglitazone reduces the contraction to ET-1 by reducing $\mathrm{ET}_{\mathrm{A}}$ and increasing $\mathrm{ET}_{\mathrm{B}}$ expres$\operatorname{sion}^{53,54}$, probably due to the fact that $\mathrm{ET}_{\mathrm{B}}$ gene is a direct target of the transcription factor PPAR $\gamma^{53}$. In agreement, we found lower levels of $\mathrm{ET}_{\mathrm{A}}$ and higher levels of $\mathrm{ET}_{\mathrm{B}}$ in vessels from pioglitazone-treated SHR that explains the $\mathrm{ET}-1 / \mathrm{ET}_{\mathrm{B}}$-dependent reduction of phenylephrine contraction in these animals. Mechanistically, this effect was due to enhanced NO production as demonstrated by the greater effect of L-NAME on phenylephrine contraction and by the augmented $\mathrm{ET}_{\mathrm{B}}$-dependent $\mathrm{NO}$ release in vessels from pioglitazone-treated SHR.

It has been described that PPAR $\gamma$ agonists reduce oxidative stress ${ }^{4,5,55,56}$. Here we found that pioglitazone treatment reduced the ET-1-induced oxidative stress in SHR vessels and VSMCs; then, we can conclude that the increased NO availability observed after pioglitazone treatment likely results from its antioxidant effects. This might also explain the reduction of ET-1-induced COX-2 expression observed in VSMCs from SHR, which is highly dependent on ROS, as demonstrated in this study. This is consistent with the reduction of COX-2 expression induced by several proinflammatory stimuli after PPAR $\gamma$ activation ${ }^{3-5}$. What is more, pioglitazone also reduced ET-1-induced PGIS levels. Furthermore, pioglitazone attenuated NFkB and AP-1 activation induced by ET-1. In agreement, SMC PPAR $\gamma$ reduces proinflammatory gene expression by inhibition of NFKB activity by promoting p 65 nuclear export ${ }^{57}$ but to our knowledge, this is the first time that interference of pioglitazone with ET-1-induced AP-1 activation is described.

\section{Conclusion}

Our results suggest that reduction of NO bioavailability and increased COX-2-derived $\mathrm{PGI}_{2}$ production, both mediated by oxidative stress, contribute to the hypercontractility to phenylephrine induced by ET-1 acting on $\mathrm{ET}_{\mathrm{A}}$ in vessels from hypertensive animals (Fig. 10). Treatment with pioglitazone along with reducing the ET-1 levels previously described ${ }^{5}$, also decreases $\mathrm{ET}_{\mathrm{A}}$ levels while increases those of $\mathrm{ET}_{\mathrm{B}}$; in these conditions, ET-1 through $\mathrm{ET}_{\mathrm{B}}$ increases the NO production. Additionally, pioglitazone reduces the ET-1-induced oxidative stress, contributing to increase NO bioavailability and to decrease COX-2 expression. All these mechanisms are responsible for the reduction of phenylephrine contraction induced by ET-1 after pioglitazone treatment (Fig. 10). These effects of glitazones on the ET-1 pathway would contribute to improve the cardiovascular alterations observed in hypertension and in other pathological diseases such as diabetes or cardiac hypertrophy ${ }^{32,49,55,58}$. Although ET-1 receptor antagonists have been demonstrated to be useful in the treatment of hypertension, they have not been approved yet in the clinic due to their side effects ${ }^{59}$. Because of the ability of pioglitazone to interfere with ET-1 system as well as to increase peripheral insulin sensitivity, this compound might be a promising therapeutic option in patients with resistant hypertension and in those with hypertension concomitant with insulin resistance. 

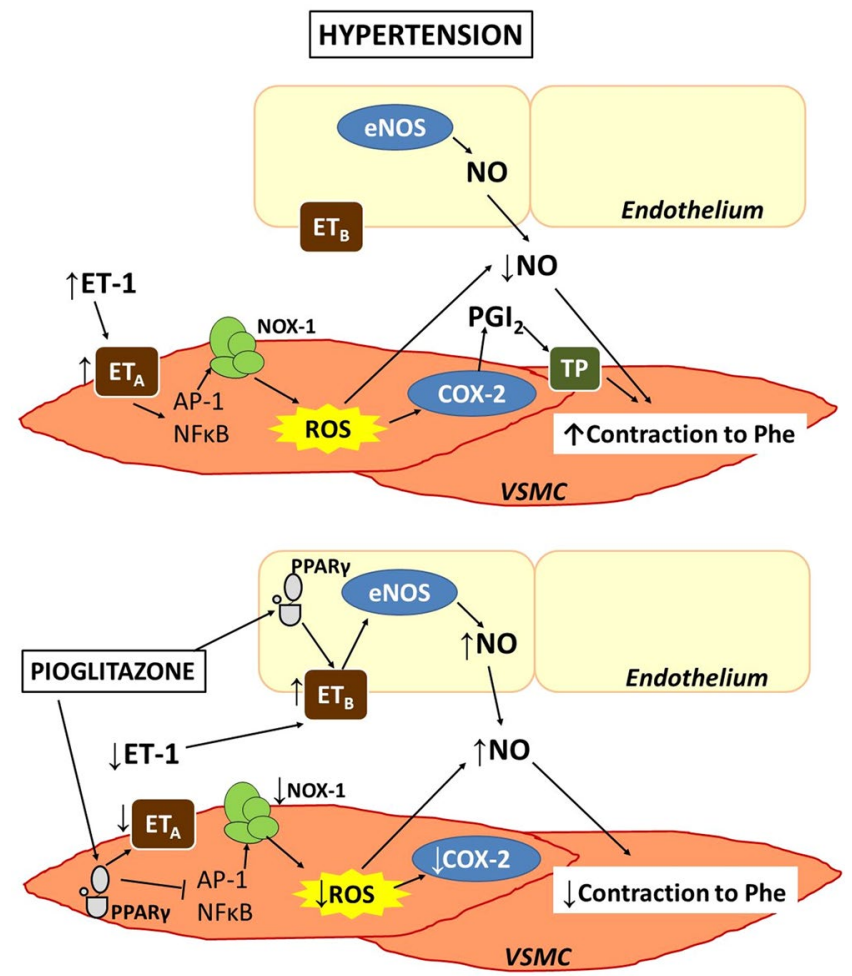

Figure 10. Scheme illustrating the proposed mechanism by which ET-1 increases phenylephrine-induced contraction in hypertension and the effect of PPAR $\gamma$ activation. In segments from hypertensive rats, ET-1, acting on $\mathrm{ET}_{\mathrm{A}}$ receptors, increases NOX-1 mRNA levels and NADPH oxidase activity through NFkB and AP-1 activation in vascular smooth muscle cells. This enhanced ROS production induces COX-2 expression that together with augmented PGIS expression lead to $\mathrm{PGI}_{2}$-dependent activation of TP receptors that increases the contraction induced by phenylephrine; in addition, the increased oxidative stress reduces NO bioavailability, which also contributes to ET-induced effects on phenylephrine response. After pioglitazone treatment, there is a reduction of smooth muscle $\mathrm{ET}_{\mathrm{A}}$ levels and an increase of endothelial $\mathrm{ET}_{\mathrm{B}}$. In these conditions, $\mathrm{ET}-1$, acting on $\mathrm{ET}_{\mathrm{B}}$, increases $\mathrm{NO}$ production; the reduction of oxidative stress due to attenuated NFKB and AP-1 activities induced by pioglitazone contributes to decrease COX-2 expression and to increase NO bioavailability; these mechanisms play a role in the reduction induced by ET- 1 of the phenylephrine response observed after pioglitazone treatment.

\section{Material and Methods}

Animals. All experimental procedures were approved by the Ethical Committee of Research of the Universidad Autónoma de Madrid and Dirección General de Medio Ambiente, Comunidad de Madrid, Spain (PROEX 345/14). Animal care and experimental procedures conformed to the current Spanish laws (RD 53/2013) and are also conformed to the Directive 2010/63/EU of the European Parliament for animal experiments. The studies also comply with the ARRIVE guidelines for reporting experiments involving animals. A total of 15 male WKY $(355.7 \pm 13.3 \mathrm{~g})$ and 60 SHR $(359.4 \pm 8.2 \mathrm{~g})$ rats five-six month-old were used.

Animals were obtained from colonies maintained at the Animal Quarters of the Facultad de Medicina of the Universidad Autónoma de Madrid. During treatment, rats were housed with constant room temperature, humidity and light cycle (12-h light/dark) and they had free access to tap water and were fed with standard rat chow ad libitum. The SHR rats were divided into two groups: control (received vehicle) and rats treated with the PPAR $\gamma$ agonist pioglitazone $(2.5 \mathrm{mg} / \mathrm{Kg}$.day, for 28 days suspended in $0.5 \%$ methylcellulose and administered in drinking water); this dose has been reported to achieve a concentration equivalent to that reported in humans who were administered a $15 \mathrm{mg}$ dose of pioglitazone ${ }^{60}$. Previously we have reported that this treatment did not modify either blood pressure or body weight ${ }^{10}$. At the end of the treatment, rats were killed by decapitation and the mesenteric arcade was removed and placed in Krebs Henseleit solution (KHS) of the following composition (in mM): $\mathrm{NaCl} 115.0 ; \mathrm{KCl} 4.7 ; \mathrm{CaCl}_{2} 2.5 ; \mathrm{KH}_{2} \mathrm{PO}_{4} 1.2 ; \mathrm{MgSO}_{4} .7 \mathrm{H}_{2} \mathrm{O}$ 1.2; $\mathrm{NaHCO}_{3} 25.0$; glucose 11.1 and $\mathrm{Na}_{2}$ EDTA 0.01 , maintained at $4{ }^{\circ} \mathrm{C}$ and continuously gassed with $95 \% \mathrm{O}_{2}$ and $5 \% \mathrm{CO}_{2}$. Segments of third-order branches of the mesenteric artery (MRA) were dissected free of fat and connective tissue and used for vascular function studies. Aortas were used to isolate VSMC as well as to analyse the vascular mRNA and NO levels and the NADPH oxidase activity.

Reactivity experiments. Ring segments, $2 \mathrm{~mm}$ in length, were mounted in a small vessel dual chamber myograph for isometric tension measurement ${ }^{10}$. Segments contractility was tested by an initial exposure to a high $\mathrm{K}^{+}$solution $\left(120 \mathrm{mM} \mathrm{K}^{+}\right.$-KHS, which was identical to $\mathrm{KHS}$ except that $\mathrm{NaCl}$ was replaced by $\mathrm{KCl}$ on an 
equimolar basis). The response to $\mathrm{K}^{+}$-KHS was similar $(P>0.05)$ in arteries from the three groups (in $\mathrm{mN} /$ mm: WKY: $3.04 \pm 0.07, n=15$; SHR: $3.12 \pm 0.09, n=24$; SHR pioglitazone: $3.23 \pm 0.13, n=13$ ). The presence of endothelium was determined by the ability of $10 \mu \mathrm{M}$ acetylcholine (ACh) to relax arteries precontracted with phenylephrine at a concentration that produce approximately $50 \%$ of the contraction induced by $\mathrm{K}^{+}$-KHS in each case. Thereafter, the vascular segments were incubated with $1 \mathrm{nM}$ ET-1 90 min prior to perform a cumulative concentration-response curve to phenylephrine $(0.1-30 \mu \mathrm{M})$. The effects of indomethacin, NS398, SQ29,548, SC19220, furegrelate, tranylcypromine, L-NAME and ML-171 (2-acetylphenothiazine) were analysed by their addition 30 min before the phenylephrine concentration-response curve. The effects of BQ123 and BQ788 on the ET-1-induced effect were analysed by their addition $30 \mathrm{~min}$ before ET-1. In some experiments, endothelium was mechanically removed and the effect of ET-1 on the phenylephrine response was analysed in the absence and the presence of NS398 and SQ29,548. Endothelium removal was assessed by the inability of $10 \mu \mathrm{M}$ ACh to produce vasodilation. In order to analyze the effect of ET-1 on ACh-induced relaxation, vessels were incubated for $90 \mathrm{~min}$ prior to phenylephrine contraction and then a cumulative concentration-response curve to ACh was performed; in some segments, L-NAME was added $30 \mathrm{~min}$ before phenylephrine.

Vasoconstrictor responses were expressed as a percentage of the tone generated by $\mathrm{K}^{+}$-KHS.

Cell cultures. Primary cultures of VSMC were obtained from thoracic aortas of 5-month-old SHRs. For this, aortas were aseptically removed, cleaned of fat tissue and blood cells, and placed in DMEM (Invitrogen Life Technologies, Carlsbad, CA, USA) at $4^{\circ} \mathrm{C}$ containing $2 \mathrm{mg} / \mathrm{ml}$ collagenase type 2 (Invitrogen Life Technologies), $0.1 \% \mathrm{BSA}, 200 \mathrm{U} / \mathrm{ml}$ penicillin and $200 \mu \mathrm{g} / \mathrm{ml}$ streptomycin (Sigma Chemical Co., St. Louis, MO, USA). After carefully removal of adventitia, VSMC were obtained by the explant method ${ }^{5}$. Cells from passages 3-8, made quiescent by incubation in DMEM containing $0.2 \%$ FBS for $24 \mathrm{~h}$, were used. Cells were identified as VSMCs by the typical spindle shape, by the typical "hills and valleys" distribution, and by positive immunocytochemical staining with specific monoclonal anti- $\alpha$-actin antibody (Sigma Chemical catalogue number A2547, lot 084M4795V). Cells were stimulated with $0.1 \mu \mathrm{M}$ ET-1 (for the times indicated in each case) with or without pretreatment for $18 \mathrm{~h}$ with pioglitazone or for $1 \mathrm{~h}$ with apocynin, catalase, SP600125 or lactacystin.

Protein expression determination by Western blot. The protein expression was determined by western blot in total extracts $(20-25 \mu \mathrm{g})$ or nuclear and cytosolic extracts $(15 \mu \mathrm{g})$ from VSMC. Proteins were separated by $10 \%$ SDS-PAGE and transferred to polyvinyl difluoride membranes that were incubated with rabbit polyclonal antibodies for COX-2 (1:250; Cayman Chemical, Ann Arbor, MI, USA, catalogue number 160106, lot 0439169-1), NOX-1 (1:1,000; Abcam, Cambridge, UK, catalogue number ab131088, lot GR3244226-4), p65 (1:1,000, Santa Cruz Biotechnology, Santa Cruz, CA, USA, catalogue number sc-372, lot BO513) or p-JNK1/2 (1:1,000, Cell Signaling Technology, Danvers, MA, USA, catalogue number \#9251, lot 24). After being washed, membranes were incubated with anti-rabbit (1:5,000, Bio-Rad, Laboratories, Hercules, CA, USA, catalogue number 70-6515, lot L005679A) or anti-mouse (1:5,000, StressGen, Ann Arbor, MI, USA, catalogue number SAB-100, lot 02020904) IgG antibody conjugated to horseradish peroxidase. The immunocomplexes were detected using an enhanced horseradish peroxidase-luminol chemiluminiscence system (ECL Plus, Amersham Biosciences, GE Healthcare, Little Chalfont, UK) and subjected to autoradiography (Minolta Film, Konica Minolta, Wayne, NJ, USA) or with the ChemiDoc ${ }^{\mathrm{TM}}$ MP Imaging System (Bio-Rad Laboratories). Signals on the immunoblot were quantified using the Typhoon 9210 quantification software (Amersham Biosciences) or the Image lab Software version 6.0 (Bio-Rad Laboratories). The same membrane was used to determine the expression of $\alpha$-actin (mouse, 1:250,000, Sigma Chemical Co.) and JNK2 (rabbit, 1:1,000, Cell Signalling Technology, catalogue number \#9258, lot 11) in total extract or TATA-binding protein (TBP, rabbit, 1:1,000, Santa Cruz Biotechnology, catalogue number sc-204, lot LO214) and GAPDH (mouse, 1:4,000, Calbiochem, Temecula, CA, USA, catalogue number $\mathrm{CB} 1001$, lot 2868983) in nuclear and cytosolic extracts, respectively. Data of protein expression were expressed as the ratio between signals on the immunoblot corresponding to the protein studied and that of $\alpha$-actin, JNK2 or TBP. To compare the results for protein expression, we assigned a value of 1 to the control or ET-1 situation.

Immunofluorescence. Proteins were also analysed by immunofluorescence, as previously described ${ }^{5}$. For this, VSMCs were seeded in a 24 -well culture plate with coverglasses in the bottom surface. After $60 \%$ confluence was reached, cultures were starved in DMEM with $0.1 \%$ FBS for $24 \mathrm{~h}$ and then stimulated with $0.1 \mu \mathrm{M}$ ET-1 ( $45 \mathrm{~min})$ after treatment or not with pioglitazone $(10 \mu \mathrm{M}, 18 \mathrm{~h})$. At the end of the treatment, cells were washed and fixed in $4 \%$ paraformaldehyde diluted in PBS and maintained in PBS containing $0.2 \%$ BSA. Then, cells were incubated overnight at $4{ }^{\circ} \mathrm{C}$ with rabbit polyclonal antibody anti-p65 (1:200 dilution). After being washed, red FITC-conjugated goat anti-rabbit antibody (Molecular Probes, Life Technologies, Paisley, UK) was added to the cells at 1:2,000 dilution in the dark. As negative controls we performed the protocol in cells without either primary or secondary antibodies; no staining was observed in both conditions (Fig. 5f). After washing, cells were incubated for $15 \mathrm{~min}$ with $4^{\prime}$,6-di-amidino-2-phenylindole (1:10,000, Invitrogen Life Technologies) to stain nuclei, and ProLong Gold antifade mounting reagent (Invitrogen Life Technologies) was added to the microscope slides. Then, fixed and treated cells were placed and sealed in the slides and allowed to completely dry in the dark until the next day. Immunofluorescence-stained cells were observed under a laser scanning confocal microscope (Nikon, C1plus, Nikon Instruments, Melville, NY, USA) and analysed using ImageJ software (http://rsb.info.nih. gov/ij). The fluorescence intensity of cells was measured at four preset areas per sample, and at least three independent experiments were performed.

mRNA levels determined by qRT-PCR assay. $\mathrm{ET}_{\mathrm{A}}, \mathrm{ET}_{\mathrm{B}}, \mathrm{PPAR} \gamma$ and eNOS mRNA levels were determined in mesenteric and/or aortic segments and COX-2, prostacyclin synthase (PGIS), NOX-1, NOX-4 and c-jun mRNA levels in VSMC. Total RNA was obtained by using TRIzol (Invitrogen Life Technologies). A total 
of $1 \mu \mathrm{g}$ of DNAse I treated RNA was reverse-transcribed into cDNA using the High Capacity cDNA Archive Kit (Applied Biosystems, Foster City, CA, USA) in a $50 \mu \mathrm{l}$ reaction. PCR was performed in duplicate for each sample using $0.5 \mu \mathrm{l}$ of cDNA as template, $1 \mathrm{x}$ TaqMan Universal PCR Master Mix (Applied Biosystems) and 20x of Taqman Gene Expression Assays (Applied Biosystems, COX-2: Rn00568225_m1; NOX-1: Rn00586652_m1;

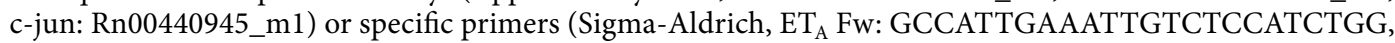
Rv: GAACTTGGTCGTGGCGTTGA; ET ${ }_{\mathrm{B}}$ Fw: GATACGACAACTTCCGCTCCA, Rv: GTCCACGATGAGG ACAATGAG; PPAR $\gamma$ Fw: TCGCTGATGCACTGCCTATG, Rv; GGAGTGGTCATCCATCACAG; eNOS Fw: GAGA GTGAGCTGGTGTTTGG, Rv: GGTGAACATTTCCTGTGCTGT; NOX-4 Fw: GCCTCCATCAAGCCAAGA, Rv: CCAGTCATCCAGTAGAGTG; PGIS Fw: CCATCAACAGCATCAAACAGTTT, Rv: CAAAGCCATATC TGCTAAGGTCAA), and Fast Start Universal SYBR Green Master (Rox) in a $20 \mu 1$ reaction. For quantification, quantitative RT-PCR was carried out in an ABI PRISM 7000 Sequence Detection System (Applied Biosystems, from the CAT of Universidad Rey Juan Carlos) using the following conditions: $2 \mathrm{~min} 50^{\circ} \mathrm{C}, 10 \mathrm{~min} 95^{\circ} \mathrm{C}$ and 40 cycles: $15 \mathrm{~s} 95^{\circ} \mathrm{C}, 1 \mathrm{~min} 60^{\circ} \mathrm{C}$. As a normalizing internal control we amplified $\beta 2$ microglobulin (Rn00560865_ $\mathrm{m} 1$ ) and cyclophilin D (Rn01458750_g1). To calculate the relative index of gene expression, we used the $2^{-\Delta \Delta \mathrm{Ct}}$ method; for comparisons, we used WKY or untreated SHR as a control situation in vascular segments and control or ET-1-treated cultures in VSMC.

In situ detection of vascular $\mathrm{O}_{2} .^{-}$production. The oxidative fluorescent dye dihydroethidium (DHE) was used to evaluate in situ $\mathrm{O}_{2} \cdot{ }^{-}$production in VSMCs, as previously described ${ }^{5}$. Hydroethidine freely permeates cells and is oxidized in the presence of $\mathrm{O}_{2} \cdot{ }^{-}$to ethidium bromide, which is trapped by intercalation with DNA. Ethidium bromide is excited at $546 \mathrm{~nm}$ and has an emission spectrum at $600-700 \mathrm{~nm}$. VSMCs were plated onto glass coverslips inserted into six-well plates and cultured as described above. Subconfluent cells were stimulated with ET-1 $(0.1 \mu \mathrm{M})$ for $1 \mathrm{~h}$ in the absence and presence of pioglitazone or apocynin that were respectively added $18 \mathrm{~h}$ or $1 \mathrm{~h}$ before ET- 1 . Afterwards, cells were loaded with DHE $(10 \mu \mathrm{M})$ in serum-free DMEM with $0.1 \%$ BSA for $30 \mathrm{~min}$ at $37^{\circ} \mathrm{C}$. Nonstimulated VSMCs were imaged daily in parallel using the same image settings. Images were captured with a fluorescent laser scanning confocal microscope (Leica TCS SP2). The fluorescence intensity values of 10-20 nuclei per experiment were measured using the Metamorph Image Analysis Software (Molecular Devices, Downingtown, PA, USA).

Lucigenin assay. A lucigenin-enhanced chemiluminescence assay was used to determine NADPH oxidase activity in aortic segments and VSMCs. Arterial segments from the same animal and VSMCs from the same batch were incubated or not with ET-1, previously treated or not with pioglitazone, lactacystin or SP600125. Aortic segments or VSMCs were homogenized in lysis buffer (in mM: $50 \mathrm{KH}_{2} \mathrm{PO}_{4}, 1$ EGTA and 150 sucrose, $\mathrm{pH}$ 7.4) on ice to avoid degradation. Protein concentration was determined by using the Bradford reactive and $50 \mu \mathrm{l}$ of the homogenate (containing $50 \mu \mathrm{g}$ protein in VSMC and $75-100 \mu \mathrm{g}$ protein in aortic segments) were transferred to a 96 well plate together with $175 \mu \mathrm{l}$ of assay phosphate buffer and lucigenin $(5 \mu \mathrm{M})$; the assay was performed by duplicate. Basal luminescence was measured every 1.8 seconds during 3 minutes in a plate luminometer (Auto-Lumat LB 953, Berthold Technologies, Bad Wildbad, Germany). The reaction was started by the addition of NADPH $(0.1 \mathrm{mM})$ and luminescence was measure every 1.8 seconds during 3 minutes. The buffer blank was subtracted from each reading. Activity was expressed as relative light units per $\mu \mathrm{g}$ of protein. Variations of luminescence were calculated as the amount relative to control or ET-1-treated arterial segments from the same animal or VSMCs from the same batch.

NO release. NO levels were analyzed in aortic segments from SHR rats with the fluorescent probe 4,5-diaminofluorescein (DAF-2), as described ${ }^{29}$; each day, one segment was used as control and others from the same animal were incubated with ET-1 previously treated or not with pioglitazone with or without BQ788. Then, vascular segments were stabilized in a Krebs-HEPES buffer (in mM: $119 \mathrm{NaCl} ; 20 \mathrm{HEPES} ; 1.2 \mathrm{CaCl}_{2} ; 4.6 \mathrm{KCl} ; 1$ $\mathrm{MgSO}_{4} ; 0.4 \mathrm{KH}_{2} \mathrm{PO}_{4} ; 5 \mathrm{NaHCO}_{3} ; 5.5$ glucose; $\left.0.15 \mathrm{Na}_{2} \mathrm{HPO}_{4}, \mathrm{pH} 7.4\right)$ at $37^{\circ} \mathrm{C}$ for $30 \mathrm{~min}$. Subsequently, segments were incubated with DAF-2 $\left(20 \mu \mathrm{M}\right.$ in Krebs-HEPES) at $37^{\circ} \mathrm{C}$ for $45 \mathrm{~min}$. Segments were made permeable with $0.05 \%$ triton for $3 \mathrm{~min}$, and the levels of $\mathrm{NO}$ were measured using a fluorometer (FLUOstar OPTIMA, BGM Labtech, Ortenberg, Germany). To analyze the effect of ET-1 on ACh-induced NO release, some segments were incubated with phenylephrine $(1 \mu \mathrm{M}, 5 \mathrm{~min})$ and $\mathrm{ACh}(10 \mu \mathrm{M}, 10 \mathrm{~min})$. Thereafter, the medium was collected to measure agonist-induced NO release. The induced NO release was calculated by subtracting basal NO release from that evoked by ACh. At the end of the experiments, aortic segments were weighted to correct the NO release. For negative controls, one segment was incubated as above indicated with $0.1 \mathrm{mM} \mathrm{L-NAME}$. A tube without aortic segment was included as blank. The amount of NO released was expressed as arbitrary units per mg of dry tissue. Variations of NO release were calculated as the amount relative to control or ET-1-treated segments from the same animal.

Data analysis. All values are expressed as mean \pm standard error (S.E.M.); $n$ denotes the number of animals or the number of different cultures (each one obtained from three different animals) used in each experiment. In vascular reactivity experiments, the maximum response (Emax values) and the negative logarithm of concentrations of phenylephrine producing $50 \%$ of maximum response $\left(\mathrm{pD}_{2}\right.$ values), were calculated by a non-linear regression analysis of each individual concentration-response curve using a computer program (GraphPad Prism Software, San Diego, CA, USA). To compare the effects of L-NAME or endothelium removal on the response to phenylephrine in segments from different groups, results are also expressed as differences of area under the concentration-response curve (dAUC) in control and experimental situations. AUCs were calculated from the individual concentration-response curve plots using the GraphPad Prism Software; the differences were expressed as a percentage of the AUC of the corresponding control situation. In the cell culture experiments, 
since the different wells of one plate have been seeded with the same batch of cells, we consider the other wells as the same subject; therefore, data are expressed as a n-fold increase relative to control in each plate, value of which was 1 . Results were analysed by using Student's t-test or two-way ANOVA with or without repeated measures followed by Tukey or Sidak test for multiple comparisons by using the GraphPad Prism Software version 7.04. $P$ $\leq 0.05$ was considered as significant differences.

Materials. Phenylephrine, ACh, SC19220, furegrelate, tranylcypromine, L-NAME, ML-171, catalase, lactacystin, SP600125, indomethacin, BQ123 and BQ788 were obtained from Sigma Chemical, Co. NS398 was obtained from Calbiochem-Novabiochem GmbH (Bad Soden, Germany), apocynin from Fluka-Sigma Chemical (Seelze, Germany) and SQ29,548 from Cayman Chemical. Pioglitazone was generously supplied by Takeda-Lilly, Madrid, Spain.

\section{Data availability}

All data generated or analyzed during this study are included in this article (and its Supplementary Information file).

Received: 17 January 2019; Accepted: 11 September 2019;

Published online: 11 November 2019

\section{References}

1. Grygiel-Gorniak, B. Peroxisome proliferator-activated receptors and their ligands: nutritional and clinical implications-a review. Nutr. J. 13, 17, https://doi.org/10.1186/1475-2891-13-17 (2014).

2. Ketsawatsomkron, P. \& Sigmund, C. D. Molecular mechanisms regulating vascular tone by peroxisome proliferator activated receptor gamma. Curr. Opin. Nephrol. Hypertens. 24, 123-130, https://doi.org/10.1097/MNH.0000000000000103 (2015).

3. Montezano, A. C., Amiri, F., Tostes, R. C., Touyz, R. M. \& Schiffrin, E. L. Inhibitory effects of PPAR-gamma on endothelin-1induced inflammatory pathways in vascular smooth muscle cells from normotensive and hypertensive rats. J. Am. Soc. Hypertens. 1, 150-160, https://doi.org/10.1016/j.jash.2007.01.005 (2007).

4. Martin, A. et al. Peroxisome proliferator-activated receptor-gamma activation reduces cyclooxygenase-2 expression in vascular smooth muscle cells from hypertensive rats by interfering with oxidative stress. J. Hypertens. 30, 315-326, https://doi.org/10.1097/ HJH.0b013e32834f043b (2012).

5. Perez-Giron, J. V. et al. Pioglitazone reduces angiotensin II-induced COX-2 expression through inhibition of ROS production and ET-1 transcription in vascular cells from spontaneously hypertensive rats. Am. J. Physiol. Heart Circ. Physiol. 306, H1582-1593, https://doi.org/10.1152/ajpheart.00924.2013 (2014).

6. Idris-Khodja, N. et al. Vascular smooth muscle cell peroxisome proliferator-activated receptor gamma protects against endothelin1-induced oxidative stress and inflammation. J. Hypertens. 35, 1390-1401, https://doi.org/10.1097/HJH.0000000000001324 (2017).

7. Touyz, R. M. \& Schiffrin, E. L. Peroxisome proliferator-activated receptors in vascular biology-molecular mechanisms and clinical implications. Vascul Pharmacol. 45, 19-28, https://doi.org/10.1016/j.vph.2005.11.014 (2006).

8. Diep, Q. N. et al. Structure, endothelial function, cell growth, and inflammation in blood vessels of angiotensin II-infused rats: role of peroxisome proliferator-activated receptor-gamma. Circulation 105, 2296-2302, https://doi.org/10.1161/01. CIR.0000016049.86468.23 (2002).

9. Shinzato, T., Ohya, Y., Nakamoto, M., Ishida, A. \& Takishita, S. Beneficial effects of pioglitazone on left ventricular hypertrophy in genetically hypertensive rats. Hypertens. Res. 30, 863-873, https://doi.org/10.1291/hypres.30.863 (2007).

10. Hernanz, R. et al. Pioglitazone treatment increases COX-2-derived prostacyclin production and reduces oxidative stress in hypertensive rats: role in vascular function. Br. J. Pharmacol. 166, 1303-1319, https://doi.org/10.1111/j.1476-5381.2012.01825.x (2012).

11. Yanagisawa, M. et al. A novel potent vasoconstrictor peptide produced by vascular endothelial cells. Nature 332, 411-415, https:// doi.org/10.1038/332411a0 (1988)

12. Davenport, A. P. et al. Endothelin. Pharmacol. Rev. 68, 357-418, https://doi.org/10.1124/pr.115.011833 (2016).

13. Horinouchi, T., Terada, K., Higashi, T. \& Miwa, S. Endothelin receptor signaling: new insight into its regulatory mechanisms. J. Pharmacol. Sci. 123, 85-101, https://doi.org/10.1254/jphs.13R02CR (2013).

14. Ahmed, M. \& Rghigh, A. Polymorphism in Endothelin-1 Gene: An Overview. Curr. Clin. Pharmacol. 11, 191-210, https://doi.org/ $10.2174 / 1574884711666160701000900(2016)$

15. Pollock, D. M. 2013 Dahl Lecture: American Heart Association council for high blood pressure research clarifying the physiology of endothelin. Hypertension 63, e110-7, https://doi.org/10.1161/HYPERTENSIONAHA.114.02441 (2014).

16. Laffin, L. J. \& Bakris, G. L. Endothelin antagonism and hypertension: an evolving target. Semin. Nephrol. 35, 168-175, https://doi. org/10.1016/j.semnephrol.2015.03.001 (2015).

17. Boesen, E. I. Endothelin receptors, renal effects and blood pressure. Curr. Opin. Pharmacol. 21, 25-34, https://doi.org/10.1016/j. coph.2014.12.007 (2015).

18. Montanari, A. et al. Endothelin-A receptors mediate renal hemodynamic effects of exogenous Angiotensin II in humans. Hypertension 42, 825-830, https://doi.org/10.1161/01.HYP.0000088361.26773.08 (2003).

19. Adiarto, S. et al. ET-1 from endothelial cells is required for complete angiotensin II-induced cardiac fibrosis and hypertrophy. Life Sci. 91, 651-657, https://doi.org/10.1016/j.lfs.2012.02.006 (2012).

20. Correa, M. V. et al. Endogenous endothelin 1 mediates angiotensin II-induced hypertrophy in electrically paced cardiac myocytes through EGFR transactivation, reactive oxygen species and NHE-1. Pflugers Arch. 466, 1819-1830, https://doi.org/10.1007/s00424013-1413-y (2014).

21. Yang, Z. H. et al. Threshold concentrations of endothelin-1 potentiate contractions to norepinephrine and serotonin in human arteries. A new mechanism of vasospasm? Circulation 82, 188-195, https://doi.org/10.1161/01.CIR.82.1.188 (1990).

22. Garcia-Villalon, A. L. et al. Endothelin-1 potentiation of coronary artery contraction after ischemia-reperfusion. Vascul Pharmacol. 48, 109-114, https://doi.org/10.1016/j.vph.2008.01.003 (2008).

23. Sanchez, A. et al. Endothelin A (ET(A)) receptors are involved in augmented adrenergic vasoconstriction and blunted nitric oxidemediated relaxation of penile arteries from insulin-resistant obese zucker rats. J. Sex. Med. 11, 1463-1474, https://doi.org/10.1111/ jsm.12526 (2014).

24. Romero, M. et al. Vascular superoxide production by endothelin-1 requires Src non-receptor protein tyrosine kinase and MAPK activation. Atherosclerosis 212, 78-85, https://doi.org/10.1016/j.atherosclerosis.2010.04.031 (2010).

25. Sanchez, A. et al. Endothelin-1 contributes to endothelial dysfunction and enhanced vasoconstriction through augmented superoxide production in penile arteries from insulin-resistant obese rats: role of ET(A) and ET(B) receptors. Br. J. Pharmacol. 171, 5682-5695, https://doi.org/10.1111/bph.12870 (2014).

26. Thengchaisri, N., Hein, T. W., Ren, Y. \& Kuo, L. Endothelin-1 impairs coronary arteriolar dilation: Role of p38 kinase-mediated superoxide production from NADPH oxidase. J. Mol. Cell. Cardiol. 86, 75-84, https://doi.org/10.1016/j.yjmcc.2015.07.014 (2015). 
27. Viel, E. C., Benkirane, K., Javeshghani, D., Touyz, R. M. \& Schiffrin, E. L. Xanthine oxidase and mitochondria contribute to vascular superoxide anion generation in DOCA-salt hypertensive rats. Am. J. Physiol. Heart Circ. Physiol. 295, H281-288, https://doi. org/10.1152/ajpheart.00304.2008 (2008).

28. Alvarez, Y., Briones, A. M., Balfagon, G., Alonso, M. J. \& Salaices, M. Hypertension increases the participation of vasoconstrictor prostanoids from cyclooxygenase-2 in phenylephrine responses. J. Hypertens. 23, 767-777, https://doi.org/10.1097/01. hih.0000163145.12707.63 (2005).

29. Martinez-Revelles, S. et al. Reciprocal relationship between reactive oxygen species and cyclooxygenase- 2 and vascular dysfunction in hypertension. Antioxid. Redox Signal. 18, 51-65, https://doi.org/10.1089/ars.2011.4335 (2013).

30. Virdis, A. et al. Endothelial dysfunction in small arteries of essential hypertensive patients: role of cyclooxygenase-2 in oxidative stress generation. Hypertension 62, 337-344, https://doi.org/10.1161/HYPERTENSIONAHA.111.00995 (2013).

31. Delerive, P. et al. Peroxisome proliferator-activated receptor activators inhibit thrombin-induced endothelin-1 production in human vascular endothelial cells by inhibiting the activator protein-1 signaling pathway. Circ. Res. 85, 394-402, https://doi.org/10.1161/01. RES.85.5.394 (1999).

32. Venegas-Pont, M. et al. Rosiglitazone decreases blood pressure and renal injury in a female mouse model of systemic lupus erythematosus. Am. J. Physiol. Regul. Integr. Comp. Physiol. 296, R1282-1289, https://doi.org/10.1152/ajpregu.90992.2008 (2009).

33. Feletou, M., Verbeuren, T. J. \& Vanhoutte, P. M. Endothelium-dependent contractions in SHR: a tale of prostanoid TP and IP receptors. Br. J. Pharmacol. 156, 563-574, https://doi.org/10.1111/j.1476-5381.2008.00060.x (2009).

34. Sutcliffe, A. M. et al. Transcriptional regulation of monocyte chemotactic protein-1 release by endothelin-1 in human airway smooth muscle cells involves NF-kappaB and AP-1. Br. J. Pharmacol. 157, 436-450, https://doi.org/10.1111/j.1476-5381.2009.00143.x (2009).

35. Hsieh, H. L., Lin, C. C., Chan, H. J., Yang, C. M. \& Yang, C. M. c-Src-dependent EGF receptor transactivation contributes to ET-1induced COX-2 expression in brain microvascular endothelial cells. J. Neuroinflammation 9, 152, https://doi.org/10.1186/17422094-9-152 (2012).

36. Ricote, M. \& Glass, C. K. PPARs and molecular mechanisms of transrepression. Biochim. Biophys. Acta 1771, 926-935, https://doi. org/10.1016/j.bbalip.2007.02.013 (2007).

37. Gomez-Guzman, M. et al. Epicatechin lowers blood pressure, restores endothelial function, and decreases oxidative stress and endothelin-1 and NADPH oxidase activity in DOCA-salt hypertension. Free Radic. Biol. Med. 52, 70-79, https://doi.org/10.1016/j. freeradbiomed.2011.09.015 (2012).

38. Maki, S. et al. The endothelin receptor antagonist ameliorates the hypertensive phenotypes of transgenic hypertensive mice with renin-angiotensin genes and discloses roles of organ specific activation of endothelin system in transgenic mice. Life Sci. 74, 1105-1118, https://doi.org/10.1016/j.lfs.2003.07.034 (2004).

39. Rautureau, Y. et al. Inducible human endothelin-1 overexpression in endothelium raises blood pressure via endothelin type A receptors. Hypertension 66, 347-355, https://doi.org/10.1161/HYPERTENSIONAHA.115.05168 (2015).

40. Wingard, C. J., Husain, S., Williams, J. \& James, S. RhoA-Rho kinase mediates synergistic ET-1 and phenylephrine contraction of rat corpus cavernosum. Am. J. Physiol. Regul. Integr. Comp. Physiol. 285, R1145-1152, https://doi.org/10.1152/ajpregu.00329.2003 (2003).

41. Cao, L., Cao, Y. X., Xu, C. B. \& Edvinsson, L. Altered endothelin receptor expression and affinity in spontaneously hypertensive rat cerebral and coronary arteries. PLoS One 8, e73761, https://doi.org/10.1371/journal.pone.0073761 (2013).

42. Garcia-Villalon, A. L. et al. Role of endothelin receptors, calcium and nitric oxide in the potentiation by endothelin-1 of the sympathetic contraction of rabbit ear artery during cooling. Br. J. Pharmacol. 121, 1659-1664, https://doi.org/10.1038/sj.bjp.0701324 (1997).

43. Zerrouk, A., Champeroux, P., Safar, M. \& Brisac, A. M. Role of endothelium in the endothelin-1-mediated potentiation of the norepinephrine response in the aorta of hypertensive rats. J. Hypertens. 15, 1101-1111 (1997).

44. Seo, B. \& Luscher, T. F. ETA and ETB receptors mediate contraction to endothelin-1 in renal artery of aging SHR. Effects of FR139317 and bosentan. Hypertension 25, 501-506, https://doi.org/10.1161/01.HYP.25.4.501 (1995).

45. Hernanz, R., Briones, A. M., Salaices, M. \& Alonso, M. J. New roles for old pathways? A circuitous relationship between reactive oxygen species and cyclo-oxygenase in hypertension. Clin. Sci. (Lond) 126, 111-121, https://doi.org/10.1042/CS20120651 (2014).

46. Gasparian, A. V. et al. Targeting transcription factor NFkappaB: comparative analysis of proteasome and IKK inhibitors. Cell. Cycle 8, 1559-1566, https://doi.org/10.4161/cc.8.10.8415 (2009).

47. Lin, C. C. et al. Upregulation of COX-2/PGE2 by ET-1 mediated through Ca2+-dependent signals in mouse brain microvascular endothelial cells. Mol. Neurobiol. 49, 1256-1269, https://doi.org/10.1007/s12035-013-8597-1 (2014).

48. Chen, D., Balyakina, E. V., Lawrence, M., Christman, B. W. \& Meyrick, B. Cyclooxygenase is regulated by ET-1 and MAPKs in peripheral lung microvascular smooth muscle cells. Am J Physiol Lung Cell Mol Physiol. 2003 284, L614-L621, https://doi. org/10.1152/ajplung.00215.2002 (2003).

49. Sakai, S. et al. Peroxisome proliferator-activated receptor-gamma activators inhibit endothelin-1-related cardiac hypertrophy in rats. Clin. Sci. (Lond) 103(Suppl 48), 16S-20S, https://doi.org/10.1042/CS103S016S (2002).

50. Halabi, C. M. et al. Interference with PPAR gamma function in smooth muscle causes vascular dysfunction and hypertension. Cell. Metab. 7, 215-226, https://doi.org/10.1016/j.cmet.2007.12.008 (2008).

51. Bao, Y. et al. Activation of peroxisome proliferator-activated receptor gamma inhibits endothelin-1-induced cardiac hypertrophy via the calcineurin/NFAT signaling pathway. Mol. Cell. Biochem. 317, 189-196, https://doi.org/10.1007/s11010-008-9848-8 (2008).

52. Huang, Y. et al. Suppression of endothelin-1-induced cardiac myocyte hypertrophy by PPAR agonists: role of diacylglycerol kinase zeta. Cardiovasc. Res. 90, 267-275, https://doi.org/10.1093/cvr/cvq401 (2011).

53. Tian, J. et al. Rosiglitazone attenuates endothelin-1-induced vasoconstriction by upregulating endothelial expression of endothelin B receptor. Hypertension 56, 129-135, https://doi.org/10.1161/HYPERTENSIONAHA.110.150375 (2010).

54. Liu, Y., Tian, X. Y., Huang, Y. \& Wang, N. Rosiglitazone Attenuated Endothelin-1-Induced Vasoconstriction of Pulmonary Arteries in the Rat Model of Pulmonary Arterial Hypertension via Differential Regulation of ET-1 Receptors. PPAR Res. 2014, 374075, https://doi.org/10.1155/2014/374075 (2014).

55. Matsumoto, T., Noguchi, E., Kobayashi, T. \& Kamata, K. Mechanisms underlying the chronic pioglitazone treatment-induced improvement in the impaired endothelium-dependent relaxation seen in aortas from diabetic rats. Free Radic. Biol. Med. 42, 993-1007, https://doi.org/10.1016/j.freeradbiomed.2006.12.028 (2007).

56. Kong, X. et al. Pioglitazone enhances the blood pressure-lowering effect of losartan via synergistic attenuation of angiotensin IIinduced vasoconstriction. J. Renin Angiotensin Aldosterone Syst. 15, 259-270, https://doi.org/10.1177/1470320313489061 (2014).

57. Mukohda, M. et al. Hypertension-Causing Mutation in Peroxisome Proliferator-Activated Receptor gamma Impairs Nuclear Export of Nuclear Factor-kappaB p65 in Vascular Smooth Muscle. Hypertension 70, 174-182, https://doi.org/10.1161/ HYPERTENSIONAHA.117.09276 (2017).

58. Yang, J., Zhou, Y. \& Guan, Y. PPARgamma as a therapeutic target in diabetic nephropathy and other renal diseases. Curr. Opin. Nephrol. Hypertens. 21, 97-105, https://doi.org/10.1097/MNH.0b013e32834de526 (2012).

59. Yuan, W. et al. Endothelin-receptor antagonist can reduce blood pressure in patients with hypertension: a meta-analysis. Blood Press. 26, 139-149, https://doi.org/10.1080/08037051.2016.1208730 (2017).

60. Ishibashi, M. et al. Antiinflammatory and antiarteriosclerotic effects of pioglitazone. Hypertension 40, 687-693, https://doi. org/10.1161/01.HYP.0000036396.64769.C2 (2002). 


\section{Acknowledgements}

We thank the Animal Care Facility of the Faculty of Ciencias de la Salud (URJC); in addition, we also thank the contribution of Daniel Horrillo, Ismael Velasco and L. Alejandro Meca for their technical assistance. The authors dedicate this work to the memory of Dr. Jose Vicente Pérez-Girón, who died on 29th March 2016. This work was supported by the Spanish Ministerio de Ciencia, Innovación y Universidades (SAF2015-69294-R and SAF201680305-P), Instituto de Salud Carlos III (CIBER de Enfermedades Cardiovasculares, CB16.11.00286), Comunidad de Madrid (B2017/BMD-3676) and Fondo Europeo de Desarrollo Regional (FEDER) a way to build Europe.

\section{Author contributions}

J.V.P.-G., R.H. and M.J.A. designed the research study; R.P., R.H., A.M., M.T.B., Z.G.-C. and A.A. performed the experimental work; R.P., R.H. and M.J.A. wrote the paper; R.P., R.H., A.M., J.V.P.-G., M.T.B., Z.G.-C., A.A., F.J., A.M.B., M.S. and M.J.A. approved the MS.

\section{Competing interests}

The authors declare no competing interests.

\section{Additional information}

Supplementary information is available for this paper at https://doi.org/10.1038/s41598-019-52839-6.

Correspondence and requests for materials should be addressed to M.J.A.

Reprints and permissions information is available at www.nature.com/reprints.

Publisher's note Springer Nature remains neutral with regard to jurisdictional claims in published maps and institutional affiliations.

(c) (i) Open Access This article is licensed under a Creative Commons Attribution 4.0 International License, which permits use, sharing, adaptation, distribution and reproduction in any medium or format, as long as you give appropriate credit to the original author(s) and the source, provide a link to the Creative Commons license, and indicate if changes were made. The images or other third party material in this article are included in the article's Creative Commons license, unless indicated otherwise in a credit line to the material. If material is not included in the article's Creative Commons license and your intended use is not permitted by statutory regulation or exceeds the permitted use, you will need to obtain permission directly from the copyright holder. To view a copy of this license, visit http://creativecommons.org/licenses/by/4.0/.

(C) The Author(s) 2019 